\title{
Laser Transmission Welding of Aluminum Film Coated With Heat Sealable Co-Polyester Resin With Polypropylene Films For Applications In Food \& Drug Packaging
}

\section{Annamaria Gisario}

Sapienza Università degli Studi di Roma

\section{Clizia Aversa}

Università degli Studi Roma Tre

Massimiliano Barletta ( $\square$ massimiliano.barletta@uniroma3.it )

Universita degli Studi Roma Tre https://orcid.org/0000-0002-1277-8034

\section{Stefano Natali}

Sapienza Università degli Studi di Roma

\section{Francesco Veniali}

Sapienza Università degli Studi di Roma

\section{Research Article}

Keywords: Laser Transmission Welding, Joining, Aluminum, Polyester Resin, Polypropylene

Posted Date: November 30th, 2021

DOI: https://doi.org/10.21203/rs.3.rs-1079639/v1

License: (c) (1) This work is licensed under a Creative Commons Attribution 4.0 International License. Read Full License

Version of Record: A version of this preprint was published at The International Journal of Advanced Manufacturing Technology on February 21st, 2022. See the published version at https://doi.org/10.1007/s00170-022-08907-9. 


\section{Abstract}

The present work deals with the high-power diode laser joining process of aluminum films coated with a polyester resin with polypropylene (PP) films. The first part of the work focused on analyzing the coating process of aluminum films with a polyester resin, using an automatic applicator. The second part of the work was focused on the analysis of the laser joining process of coated aluminum films with plastic counterparts made of PP. Different thicknesses and colors of the PP parts were tested in order to analyze the joining process under a wide range of different conditions. The experimental plan involved the study of the influence of the laser joining parameters, in particular the scanning speed and beam power, on the joints. The joints between aluminum and PP films were subsequently tested by means of tensile and peeloff tests. The results allowed the detection of the best processing conditions, stating the high potential of laser systems in the joining process of aluminum and PP films for food packaging applications.

\section{Introduction}

Laser welding of plastics belong to the class of advanced technologies for joining films, sheets, semirigid and rigid components made of polymeric materials by localized heating with a focused beam of laser radiation (Moskvitin, Polyakov, \& Birger, 2013). The first applications of such technology date back to the seventies of the last century, although the related processing solutions were well established only after 25 years (Volkov \& Chernyak, 1987). The high potential of the laser welding applied to plastic materials embrace: (i) the lack of contact between the heating source and the substrates to join (Brown, Kerr, Parkin, \& Jackson, 2012), in contrast with the conventional welding processes (Najarzadeh \& Ajji, 2004), (Stokes \& Conway, 2001); (ii) the option of joining substrates that are different in geometry, chemical composition and/or color (Brown, Shi, Kerr, Jackson, \& Parkin, 2003); (iii) the good visual appearance and high endurance of the welded joints (Liu, Ouyang, Zhao, Li, \& Sun, 2018). Additional benefits of the laser welding of plastics encompass: (i) the option to weld areas that are, otherwise, complex to reach with traditional processes and, consequently, the easy-route to the process automation (Brunnecker, 2018) sizing it according to the production requirements; (ii) limited needs of labor force/skilled technicians (Tillmann, Elrefaey, \& Wojarski, 2010); (iii) reduced energy and non-renewable resources (Sproesser, Chang, Pittner, Finkbeiner, \& Rethmeier, Life Cycle Assessment of welding technologies for thick metal plate welds, 2015); (iv) high operational safety (Brown, Kerr, Jackson, \& R.M., 2000); (v) very low environmental impact during the operations (Sproesser, Chang, Pittner, Finkbeiner, \& Rethmeier, Sustainable technologies for thick metal plate welding, 2017), (Sproesser, Chang, Pittner, Finkbeiner, \& Rethmeier, Life Cycle Assessment of welding technologies for thick metal plate welds, 2015). In particular, laser welding are often applied to the joining of polymeric films and to the hermetic sealing of metallic films with polymeric films or semi-rigid and/or rigid containers (Brown, Kerr, Parkin, \& Jackson, 2012), (Brown, Shi, \& Jackson, CO2 laser processing of multilayer packaging films, 2005). More recently, the use of laser welding have also been extended to bioplastic materials (Ljungberg, Andersson, \& Wesslen, 2003), (Fiorini, Campana, Pagano, \& Morelli, 2015) in order to join them with metals such as, for example, aluminum alloys (Pagano, Campana, Fiorini, \& Morelli, 2017). 
Laser transmission welding of plastics can be performed by focusing the laser beam on the joint in two different ways: (i) the laser beam is irradiated to be tangent to the joint interface between the two materials that compose the assembly, of which, at least, one is able to capture the radiation (Acherjee, Laser transmission welding of polymers - A review on process fundamentals, material attributes, weldability, and welding techniques, 2020); (ii) the laser beam is irradiated normal to the joint interface across a laser-transparent material, provided that the other material of the assembly or the material posed at the interface is able to absorb the radiation. Laser transmission welding involves, therefore, light absorption, heat generation, heat conduction, melting, mixing, and re-solidification (Ghorbel, 2009). Different joint configurations were investigated in the literature (Acherjee, Laser transmission welding of polymers - A review on process fundamentals, material attributes, weldability, and welding techniques, 2020). However, when a laser transparent polymer is put on top of a laser absorbing material, the most common joint configuration is the lap joint (Jones, 2016). The T-joint is also rather common in the literature (Jones, 2016). Butt joints are seldom used because of the limited optical penetration of the laser radiation in the transparent polymer (Mingareev, 2012). In this case, even the application of the correct pressure between the edges of the counterparts can be extremely complicated. In fact, $\mathrm{T}$ - and butt joint configurations are often affected by the meltdown of the molten or partially molten polymeric material, especially under the pressure normally exerted on the joint interface (Ghasemi, 2018), (Prabhakaran, 2006), (Potente, 2006). The compositions of polymers can obviously affect the transmission of the laser radiation through the assembly, strongly influencing the final results together with the wavelength of the laser source (Acherjee, Laser transmission welding of polymers - A review on process fundamentals, material attributes, weldability, and welding techniques, 2020). Part thickness in the assembly can also play a crucial role, especially when a crystalline or semi-crystalline polymer is investigated. In contrast, amorphous polymers allow laser transmission across long pattern, with minimum loss of the transmittance (Rhew, 2003). Most of the thermoplastic polymers, even when reinforced, can be welded using a laser beam. Laser welding of polymers that include ABS (acryl butadiene styrene), PC (polycarbonate), PMMA (polymethyl methacrylate), PE (polyethylene), PEI (polyethyleneimine), PS (polystyrene), POM (polyoxymethylene), PET (polyethylene terephthalate), PEEK (polyether ether ketone) and their blends are widely documented in the literature. Basically, the resulting joints feature a strength that remains comparable to the base material strength. A variety of tested polymer combinations and the related laser weldability chart is, however, summarized in (Acherjee, Laser transmission welding of polymers - A review on process fundamentals, material attributes, weldability, and welding techniques, 2020). Many of the combinations investigated in (Acherjee, Laser transmission welding of polymers - A review on process fundamentals, material attributes, weldability, and welding techniques, 2020) could not be joined by using other conventional methods of polymer welding.

Laser transmission welding of dissimilar polymers can also be carried out if both the polymers are chemically compatible, that is, they must feature similar molecular structures and analogous viscosities in their typical melting interval (Oliveira, 2014), (Acherjee \& Maity, Parameters optimisation of transmission laser welding of dissimilar plastics using RSM and flower pollination algorithm integrated approach, 2017), (Mehrpouya, 2019), (llie, 2020), (Askadskii, Matseevich, Popova, \& Kondrashchenko, 
2015). Nevertheless, in food and pharmaceutical packaging, joining of polymers with dissimilar materials, like for example metal or cellulose paper is often required. Mechanical fastening, adhesive bonding, and thermal welding are common solutions for joining parts made in different materials (Amanat, 2010), (Grewell, 2013). However, the use of mechanical fastening or adhesive bonding in medicine and food packaging is often unpractical, because of the complex joining strategy required and usage of external attachments that can be harmful. Thermal welding is therefore largely preferred to weld dissimilar parts, with heating arms or rolls that require precise positioning in order to accurately seal the counterparts in the assembly, thus slowing down the process and making it unsuitable to the large production volumes typical of drug and food industrial sector. In contrast, laser technology has recently acquired a prominent position in packaging industry (Katayama \& Kawahito, 2008), (Wang X. S., 2012), (Pagano, Campana, Fiorini, \& Morelli, 2017), (Gisario A. M., 2017), (Gisario A. V., 2017). Food and drug packaging often require joining of coated metal with plastic counterparts. Coatings on metal are often organic resin, that are used to avoid direct contact between food and/or drugs and metal to prevent erosion/corrosion issues that could be harmful to human health (Banks, W.A., Kastin, A.J., 1989), (Gupta, 2005), (Falk, 2018). The influence of the organic coating on the laser heat-sealability of the assembly is still debated. In particular, there are no studies to date that evaluate laser joints of assemblies between coated aluminum and polymeric films for food and drug packaging, like, for example, in manufacturing of prebiotic and probiotic food supplements. This is the context in which, therefore, the present work studies the applicability of the laser transmission welding to films in PP and aluminum coated with a polyester resin.

\section{Experimental}

\subsection{Coating process of aluminum films}

\subsubsection{Aluminum substrates}

The experimentation was performed using an 8006 series aluminum alloy as a substrate, widely used in food and pharmaceutical packaging. The alloy has undergone an $\mathrm{H} 22$ heat treatment. Three aluminum coils with different thicknesses were initially selected: 50,100 and $150 \mu \mathrm{m}$. The aluminum substrates were obtained, for each thickness, starting from a single aluminum coil, cut in such a way as to obtain a set of samples with dimensions equal to those of an A4 sheet $(210 \mathrm{~mm} \times 297 \mathrm{~mm})$

\subsubsection{Polyester resin}

A solvent borne thermoplastic resin suitable for food contact and resistant to moderate temperatures (up to $225^{\circ} \mathrm{C}$ for $45 \mathrm{~min}$ ) was chosen for the coating process of the aluminum substrate. It is a transparent co-polyester resin modified with the addition of compatibilizer that features functional groups of high chemical affinity with the polyolefins. The resin is heat sealable. The supplier company is Metlac Group Spa (Italy) which has marked the product with the reference code 815611. 


\subsubsection{Coating process of the aluminum substrates with the polyester resin}

The aluminum substrates were subjected to a preliminary degreasing operation by immersion in an ultrasonic tank inside an acetone-based solution. The coating process of the aluminum substrates was carried out using an automatic film applicator (model 2105 Automatic Film Applicator S, BYK-Gardner). The applicator is equipped with a vacuumed work surface that allows to ensure the adhesion of the aluminum film during the application of the resin. The resin is spread by feeding the resin with a graduated injector on the initial part of the surface of the aluminum substrate, along a line orthogonal to the advancement of the automatic applicator blade. The resin is subsequently distributed homogeneously on the aluminum surface, by means of a blade that advances right along the work surface of the automatic applicator, orthogonally to the aforementioned resin feeding direction. The coating thickness is modulated by adjusting the distance of the automatic applicator blade with respect to the work surface. This adjustment is carried out by means of micrometric screws, which can allow the fine adjustment of the thickness (in steps of about five microns). More precisely, the coating process was carried out through subsequent steps, progressively reducing the distance between the blade and the work surface of the automatic applicator. The application of the resin through subsequent steps allowed to improve the overall quality of the lacquer and to obtain a better homogeneity of the resin distribution on the aluminum surface. Two strategies were used to coat the aluminum substrates with the polyester resin. In the first case, two coating passes were carried out, adjusting the distance between the blade and the work surface at 200 and $150 \mu \mathrm{m}$ (first test, double pass) and at 250 and $180 \mu \mathrm{m}$ (second test, double pass). In the second case, three coating passes were carried out, adjusting the distance between the blade and the work surface of the automatic applicator at 200, 180 and $150 \mu \mathrm{m}$ (first test, triple pass) and at 250, 200 and $180 \mu \mathrm{m}$ (second test, triple pass), respectively. In all the coating tests, the amount of resin is kept constant and in net excess compared to what is theoretically necessary to coat the entire aluminum support. Specifically, the amount of resin used was approximately $6.237 \mathrm{ml}$ for all the tests performed. Basically, the surface of the aluminum support is $0.06237 \mathrm{~m}^{2}$ (i.e. $0.21 \times 0.297 \mathrm{~m}^{2}$ ). Since the resin density is approximately $1 \mathrm{~kg} / \mathrm{m}^{3}, 6.237 \mathrm{ml}$ of resin correspond to a coating weight of approximately $100 \mathrm{~g} / \mathrm{m}^{2}$, or an equivalent thickness of 100 microns. Normally, the thicknesses of the lacquers used for food aluminum do not exceed 25 microns, so that a well in excess of resin is fed, compared to what is strictly necessary. Obviously, the excess resin is eventually removed by the advancement of the blade, again in relation to the adjustment of its position with respect to the work surface. The advancement speed of the automatic applicator blade during the coating process has been set at a constant value of $50 \mathrm{~mm} / \mathrm{s}$ for all tests, in order to ensure greater uniformity in the coating process. The crosslinking of the resin on the aluminum substrates took place in a drying oven for polymers (model FD, BINDER). The polymerization temperature of the lacquer was set at $160^{\circ} \mathrm{C}$ for a residence time of the films in the oven of about $20 \mathrm{sec}$.

\subsubsection{Measurement of the coating thickness}


To measure the thickness of the organic coating on the aluminum substrates, a magnetic induction thickness gauge (Mega-check 5FN-ST, Assicontrol) was used. The measurements were carried out by building a grid consisting of 24 points as shown in Figure 1, ideally arranged in such a way as to intercept the central area of the coating, excluding any edge defects due to the coating process. Furthermore, a horizontal distance of $30 \mathrm{~mm}$ was established between each point ( 6 for each row) and a vertical distance of $25 \mathrm{~mm}$ ( 4 for each column). All the measurements acquired were processed in order to build a 3D map of the coating surface using the SW OriginLab v9.0, allowing to describe the average trend of the coating thickness.

\subsection{Coated aluminum - polymer joining process by means of a high-power diode laser}

\subsubsection{Joining Assembly}

The process of joining the aluminum substrate with the polymer film was performed through the use of a high-power diode laser source described in previous works (Gisario A. V., 2017), using the so-called configuration with overlapping edges (Jones, 2016). The coated aluminum substrates were welded with PP co-polymer film, commonly used in the packaging of drugs and food. In particular, three types of PP films were chosen. The first two films have a thickness of $80 \mu \mathrm{m}$ and differ in color, which in the first case is white and in the second case is transparent. The third film selected is always in PP, has a transparent color and a thickness of $1100 \mu \mathrm{m}$. The coated aluminum samples for the welding process were made from the sheet $(210 \times 297 \mathrm{~mm})$ previously used to carry out the coating process. The samples were cut using a die. The size of each specimen was set at $30 \times 70 \mathrm{~mm}^{2}$. In particular, specimens of the same size were obtained both for coated aluminum substrates and for the various types of PP films. In particular, the cutting of the specimens was operated in accordance with the description provided in Figure 2. A total of twelve sets of specimens in lacquered aluminum were prepared which differ in the thickness of the aluminum support and the thickness of the coating. In this phase, however, it was decided to focus the experimentation on two thicknesses of the aluminum substrate, namely 50 and $150 \mu \mathrm{m}$, as the intermediate thickness $(100 \mu \mathrm{m})$ provided a behavior similar to the previous ones in the coating process. In a similar way, the PP counterparts (with the same dimensions as the aluminum samples, for which 30 $\times 70 \mathrm{~mm}^{2}$ ) were obtained by punching a PP co-polymer film with a thickness of $80 \mu \mathrm{m}$, with white color and transparent and by punching a $1100 \mu \mathrm{m}$ film with transparent color.

\subsubsection{Laser apparatus}

The laser source used in the experimentation is a diode laser (model DL 105, Rofin Sinar) with a maximum power of $1500 \mathrm{~W}$ and an elliptical spot (focal spot size $1.2 \times 3.8 \mathrm{~mm}^{2}$ ). The spot has, in particular, a Gaussian beam distribution, uniform along the major axis of the elliptical spot. The fluence is therefore calculated as the ratio of the laser power multiplied the interaction time to the area of the focal spot. The interaction time is achieved as the ratio of the spot length in the advancing direction of the beam (i.e., $3.8 \mathrm{~mm}$ of the long axis of the elliptical spot) divided by the scan speed. The system is 
described in detail in previous papers (Gisario A. V., 2017). A CNC motorized table is positioned below the laser head. It allows the movement of the samples to be welded along an axis of the welding plane (focal distance equal to $63 \mathrm{~mm}$ ) which is orthogonal to the beam, ensuring the relative motion between the samples and the beam itself. In particular, the advancement of the laser beam along the surface of the joint occurs parallel to the major axis of the elliptical spot. In this way, the thickness of the weld bead is reduced, since it will correspond, indicatively, to the smaller dimension of the elliptical spot of the beam.

\subsubsection{Clamping systems of the assembly}

To grasp the samples during the welding process, the use of two Perspex masks, a material notoriously transparent to laser radiation, was used. The samples were preliminarily positioned inside the masks and the system was then clamped with special pliers in order to impart adequate pressure in the welding area and facilitate the welding between the two PP and coated aluminum films. At the same time, this gripping system prevents the entry of air into the overlapping area of the edges of the two samples. The system was then positioned on the previously described handling table, located below the laser head. Focusing has always occurred at the interface surface between the two samples to be coupled. In Figure 3, a schematic of the gripping system is shown.

Table 1

Experimental plan used for the first and the second scenario

\begin{tabular}{|lll|}
\hline Scan speed [mm/s] & Laser power [W] & Fluence [J/mm $\left.{ }^{2}\right]$ \\
\hline 4 & 80 & 1,77 \\
\hline 7 & 120 & 1,52 \\
\hline
\end{tabular}

Table 2

Experimental plan used for the third scenario

\begin{tabular}{|lll|}
\hline $\begin{array}{l}\text { Scan speed } \\
\text { [mm/s] }\end{array}$ & Laser power [W] & Fluence [J/mm $\left.{ }^{2}\right]$ \\
\hline 4 & 190 & 4,2 \\
\hline 5 & 220 & 3,89 \\
\hline 6 & 230 & 3,39 \\
\hline 7 & 240 & 3,03 \\
\hline
\end{tabular}

\subsubsection{Experimental plan}

The first group of tests regarded the welding process between the coated aluminum supports with a thickness of $50 \mu \mathrm{m}$ and white PP films with a thickness of $80 \mu \mathrm{m}$, identifying the first reference scenario. The second group of tests concerned the welding process between the coated aluminum supports with a thickness of $50 \mu \mathrm{m}$ and transparent PP films with a thickness of $80 \mu \mathrm{m}$, identifying the second scenario. The third group of tests concerned the welding process between the coated aluminum supports with a 
thickness of $150 \mu \mathrm{m}$ and white PP films with a thickness of $1100 \mu \mathrm{m}$, identifying the third scenario. Below, Table 1 and Table 2, respectively, show the set of parameters set for the three scenarios studied. The experimental tests were performed based on a combination of the scanning speed and laser beam power such as to generate a fluence released on the sample surface, slightly decreasing (almost constant) with increasing power. This condition is necessary in order not to induce thermal degradation, since the support in polymeric material is much more sensitive to the increase in power of the laser beam.

\subsubsection{Characterization of the joints: tensile tests}

To perform tensile and peel-off tests, a static testing device (model 3367, Instron) was chosen. The static testing device was equipped with a $500 \mathrm{~N}$ load cell. All the tests were managed using the Bluehill v8.3 software. The software allows to calibrate the equipment, choose the testing parameters and obtain the load- displacement curves. As the configurations of the joining samples were characterized by the presence of overlapping edges, the performed tensile tests can be, more appropriately, considered a shear resistance test in agreement with (Kang, 2018). Deformation speeds of $0.5 \mathrm{~mm} / \mathrm{min}$ were set for the thicker coated aluminum samples $(150 \mathrm{~mm})$ in the joining process with the thicker $1100 \mathrm{~mm}$ PP film. Deformation speeds of $1.5 \mathrm{~mm} / \mathrm{min}$ were set for the tensile tests that, instead, involve the thinner lacquered aluminum films in the joining process with the thinner $80 \mathrm{~mm}$ white and transparent PP films, respectively. Figure 5 a shows the clamping system used during the tensile tests.

\subsubsection{Characterization of the joints: peel-off tests}

To test the tear strength of the different welded joints between the coated aluminum and the polymeric films, peel-off tests were also performed, using the same equipment, that is a static testing device (model 3367 , Instron). Generally, this test is carried out by imposing the stretching of the films at $90^{\circ}$ with respect to the lying of joining surface between the aluminum and polymeric films. This is, in fact, the configuration adopted in the present work. For the running of the peel-off tests, it was necessary to adapt the clamping system of the samples to the static testing device through the design of an appropriate configuration, which is better described in Figure $5 \mathrm{~b}$. Once the edge of the coated aluminum sample was fixed, the test consisted in clamping the polymeric edge with a grip. While the crossbar moved upwards at a constant speed, the static testing machine recorded the load necessary to detach the coated aluminum and the polymeric counterparts. A different caution was taken in the peel-off tests concerning the joint of the Al $150 \mu \mathrm{m}$ - PP $1100 \mathrm{~mm}$ assembly. Given the higher stiffness of the thicker PP edge, the PP edge itself was clamped with the previous clamping system and the aluminum edge was pulled-out (Figure $5 b)$. For the running of the peel-off tests, a deformation speed of $2 \mathrm{~mm} / \mathrm{min}$ has always been set.

\section{Results And Discussion}

\subsection{Analysis of laquering process}

Figure 6 shows the trend of the resin coating thickness on the aluminum substrates for all the experimental conditions investigated. It is possible to highlight a higher coating thickness for aluminum 
substrates with lower thickness. Conversely, thinner coatings thicknesses were measured for the thicker aluminum substrates. As specified in the previous section, the resin fed for all the experimental conditions is largely in excess. Choosing a thicker aluminum support means obtaining a shorter distance between the surface of the aluminum sample and the trajectory of the automatic applicator blade during the coating process. In this regard, the distance that remains set during the tests is that between the blade and the surface of the applicator work surface. Therefore, the latter being the same, having a thicker aluminum substrate means obtaining a smaller effective distance between the surface of the sample to be coated and the blade itself. Therefore, since the amount of resin used is largely in excess, it is able to saturate all the ideal volume between the surface of the aluminum support surface and the height defined by the blade that advances in the coating process. Consequently, the smaller the thickness of the aluminum support, the greater the expected thickness of the coating. Vice versa, the greater the thickness of the aluminum support, the lower the thickness of the resulting coating. The experimental data reported in Figure 6 support the previous observations, confirming the inverse proportionality relationship between the thickness of the coating and the thickness of the aluminum support, with the former increasing as the latter decreases and vice versa. Furthermore, as pointed out, the amount of resin initially fed during the coating process remained unchanged during all the tests, creating reproducible conditions for all the experimental tests performed. The differences in thickness for some samples do not generate an uneven contact. The coating surface is, in fact, always very smooth $\left(R_{a}<0,1 \mathrm{~mm}\right.$, in any case) and the difference in thickness reflect in different morphology on such a long scale that does not affect the joining process.

From the examination of the contour plots in Figure 6, it can be assumed that the coatings show a fair degree of homogeneity, although some surface defects in the flatness of the films, mainly due to the necessary handling of the samples, are still observable on large dimensional scale. These defects are reflected in islands on the surface of the coating characterized by decidedly higher or, on the contrary, lower thicknesses than the surrounding areas. The analysis of the homogeneity of the distribution of the coating thickness on the surface of the samples under study can be carried out by examining Figure 7 . The average coating thicknesses are in the range of 33 to $42 \mu \mathrm{m}$ for the aluminum substrate with the smallest thickness $(50 \mu \mathrm{m})$, while they remain in the lower range of 18 to $25 \mu \mathrm{m}$ for the aluminum substrate with the highest thickness $(150 \mu \mathrm{m})$. Finally, the average variation in thickness of the polyester resin coating applied to the aluminum substrates in the three thicknesses $(50,100$ and $150 \mu \mathrm{m})$ is, however, very limited, demonstrating the good homogeneity of the coating process. These variations amount to approximately $5 \mu \mathrm{m}$ for aluminum substrates with a thickness of $50 \mu \mathrm{m}$ and to approximately $10 \mu \mathrm{m}$ for aluminum substrates with a thickness of 100 and $150 \mu \mathrm{m}$. In only one case, a thickness variation greater than $10 \mu \mathrm{m}$ is obtained, with reference to an aluminum substrate with a thickness of 150 $\mu \mathrm{m}$ and two coating passes.

There is also an improvement in the homogeneity of the coating, by resorting to three successive coating passes compared to the two canonical passes. This result is due to the leveling effect of the blade on the surface of the coating. By resorting to an extra pass, it is possible to obtain a better leveling effect of the resin. This result can also be attributed to the increase in viscosity of the resin over time, during the 
coating process. When the resin is released onto the sample it is very fluid, as it is designed with a very low viscosity to spread easily on the aluminum surface, wetting it completely. However, when the resin is distributed on the aluminum surface, due to the effect of the blade advancing in the coating process with an automatic applicator, the surface of the resin exposed to the evaporation effect increases significantly. Evaporation concerns the volatile part of the resin formulation (the part of solvents that serves to regulate its viscosity, reducing it strongly). When this fraction of solvent begins to decrease, the resin becomes progressively less viscous, although still highly deformable. Therefore, when the blade passes a second or even a third time on the resin previously distributed on the surface of the aluminum substrate, it finds a progressively more viscous material. The blade, therefore, tends to shape the resin with greater precision, as it tends to flow less due to the increase in viscosity. This determines a significant improvement in the homogeneity of the coating thickness.

\subsection{Analysis of the welding process}

In Figure 8, the joints obtained on the aluminum/PP assembly relating to the first and second experimental scenarios are shown, i.e. the scenario that refers to aluminum with a thickness thinner than $50 \mu \mathrm{m}$ and to PP films, white and transparent, always with a thin thickness of $80 \mu \mathrm{m}$. The joint areas always show an excellent aesthetic aspect such as not to make clear, in most cases, the distinction of the area affected by the irradiation of the laser beam (i.e., the so called thermal altered zone, (Barletta, 2006)). Increasing the laser power and the scanning speed causes the onset of some surface wrinkling on the surface of the aluminum. This can be ascribable to the thermal expansion of the polymer when in molten state, followed by the contraction due to the sudden cooling after the end of the laser irradiation. The aluminum film is consequently expanded and then shrunk accordingly with corresponding internal stresses arising inside the material, this being the cause of the surface wrinkles. This phenomenon is much less apparent at lower power and scan speed, where the thermal transitions are correspondingly slower, this allowing the materials more time to adapt to the dimensional changes related to heating and cooling cycle.

Figure 9 shows the image of the joints after the laser tests conducted on aluminum and PP films with a larger thickness (Al $150 \mu \mathrm{m}$ - PP transparent $1100 \mu \mathrm{m}$ assembly). The joints exhibit an excellent aesthetic appearance, with the joint bead being barely noticeable, regardless of the process conditions examined. Incipient signs of thermal degradation can be seen only at the higher powers of the laser beam. A sort of furrow appear on the joint, specifically in the last zones of the samples that are irradiated by the laser beam. This can be ascribable to the thermal inertia phenomena. The laser starts to act on a cool sample, but the sample temperature rapidly increases during the tests. The last zone irradiated starts from a temperature which is already higher than ambient temperature as a result of the heat absorbed by the sample itself during the first moment of the laser irradiation. Therefore, the last portions of the sample irradiated are certainly more subjected to be impaired by thermal alteration damage. However, in this case, there are no significant wrinkles on the sample surface as a result of the higher thickness and stiffer response of the PP substrate.

\subsection{Tensile tests of the joints}




\subsubsection{Joints between films in Al $50 \mathrm{~mm}$ - PP $80 \mathrm{~mm}$ white and transparent}

The experimental results obtained from the tensile tests led on the joints of the aluminum-polymer joints achieved by means of a high-power diode laser are summarized. Given the welding configuration with overlapping edges of the films in aluminum and PP, the tensile test, as it was carried out, basically transposes into a shear resistance test along the welding bead in agreement with (Kang, 2018). Figure 10 shows the trends of the load vs. displacement during the tests performed for the sample set Al $50 \mu \mathrm{m}$-PP white $80 \mu \mathrm{m}$. The experimental tests performed on the aforementioned samples are compared, using two different combinations of scanning speed and laser power that generate an almost constant fluence radiated on the joint surface (i.e., experimentation in conditions of so-called iso-fluence (Barletta, 2006)). The trends of the load vs. displacement are very similar, regardless of the chosen laser parameters and the thickness of the coatings, which, in the case in question, is in the range of about $30-40 \mu \mathrm{m}$. These trends can be traced back to the classic load - displacement curve in a tensile test of a polymeric material, recalling that, in this case, the white PP takes a crucial role in the formation of the joint. In fact, these trends are not similar to the typical trends of the load vs. displacement of metallic materials, with a sudden break after the elastic-plastic section. On the contrary, there is a strong elongation with a very progressive reduction of the load. This is typical of the very flexible polymeric materials subjected to tensile stress, that shows a progressive elongation of the polymer chains (initially, of the amorphous portion of the polymer and, subsequently, of the crystalline fraction), which are oriented in the direction of application of the load. Furthermore, the fracture of the Al $50 \mu \mathrm{m}$-PP white $80 \mu \mathrm{m}$ assemblies always occur in the joining area, where the chains of the PP are elongated, up to achieve elongations of 10 to 15 $\mathrm{mm}$. Such fractures, however, occur not before the PP in the assembly has exhibited a large deformation in the plastic field. The large elongation observed is, therefore, precisely the result of the deformation of the PP film in the assembly. The load vs. displacement trend of the Al $50 \mu \mathrm{m}$-PP white $80 \mu \mathrm{m}$ assemblies, once the maximum load has been reached, decreases, as previously observed, very slowly to settle on a final load of just under $50 \mathrm{~N}$. Although there are no apparent variations in the maximum point of the load vs. displacement curves, the maximum elongation reached before the fracture is always greater if higher laser power and scan speed are set. The highest elongations at break of the welded joints with the same fluence, which are obtained by selecting the highest beam power and scanning speed, can be attributed precisely to the characteristics of the interaction between laser beam and polymeric material in the assembly. The latter is very susceptible to the action of laser radiation, which can cause rapid degradation of the polymer. When the polymer degrades, even locally as in the case under examination, a reduction of the molecular weight of the same occurs and, consequently, a loss of part of the mechanical properties of the polymer (Bodzay, 2009). Working with the same fluence radiated on the joint surface, but with greater laser power and scanning speed, means reducing the interaction times between the laser beam and the polymer itself. Probably, this reduces the thermal degradation phenomena of the polyolefin and also of the heat sealable lacquer, allowing the welding joint to exhibit a better behavior during the tensile test (Navas-Martos, 2018). However, as seen in the previous section, some wrinkles appear on the aluminum surface, because of the quick heating - cooling cycle.

Page $11 / 32$ 
Figure 11, on the other hand, compares the tests performed on films in Al $50 \mu \mathrm{m}$-PP transparent $80 \mu \mathrm{m}$. In this case, there is a general trend different from the previous one, with the joints exhibiting an elasticplastic behavior rather than visco-elastic/visco-plastic. The maximum loads are, in all cases, higher. They are higher than $100 \mathrm{~N}$, while, on the other hand, the elongations at break are lower, constantly remaining between 9 and $12 \mathrm{~mm}$. It is also observed that the combination of parameters with higher speed and laser power, respectively of $6 \mathrm{~mm} / \mathrm{s}$ and $105 \mathrm{~W}$, does not always provide a welded joint with superior characteristics, compared to the combination of parameters with lower values ( $4 \mathrm{~mm} / \mathrm{s}$ and $70 \mathrm{~W}$ ), as found in the previous case. Basically, due to the transparency of PP, the welding mechanism becomes more efficient. Meanwhile, the transparent PP does not effectively absorb the radiation from the beam, as in the previous case, in which white PP was used. The beam can easily pass through the transparent PP film and act at the interface with the aluminum, with practically unchanged power, also given the modest thicknesses of the PP films involved. In this way, it is the aluminum that heats up strongly and, subsequently, transmits the heat to the adjacent heat sealable low melting lacquer and, therefore, to the topmost film in PP (Katayama \& Kawahito, 2008).

The PP in Al $50 \mu \mathrm{m}$-PP transparent $80 \mu \mathrm{m}$ assembly is much less exposed to the direct action of the laser beam. Welding is very effective, with the co-polyester heat sealable lacquer presumably playing a major role in the weld joint. The co-polyester lacquer is, in fact, a thermoplastic resin, which substantially tends to exhibit a more rigid and brittle behavior than polyolefins, as it quickly crystallized during the tensile tests. This mitigates the tendency of the assembly to exhibit viscous behavior as seen before for the Al $50 \mu \mathrm{m}$-PP white $80 \mu \mathrm{m}$ assemblies. Consequently, the joint exhibits a greater point of maximum load in the Al $50 \mu \mathrm{m}$-PP transparent $80 \mu \mathrm{m}$ assemblies, a lower elongation at break and a trend of load vs. displacement much more similar to that of materials with an elastic-plastic behavior. Also, in this case, the failure of the welded joint occurs after the observation of a rather large deformation of the polymeric material in the plastic field. However, the elongation at break is, in this case, on average lower than that measured for the Al $50 \mu \mathrm{m}$-PP white $80 \mu \mathrm{m}$ assemblies. More details will, however, be provided upon examination of the peel-off tests carried out on the same samples.

\subsubsection{Joints between films in Al $150 \mathrm{~mm}$ - PP $1100 \mathrm{~mm}$ transparent}

Figure 12, on the other hand, shows the trend of the load vs. displacement for the Al $150 \mu \mathrm{m}$ - PP transparent $1100 \mu \mathrm{m}$ assembly. It is possible to notice a rigid - elastic trend. The higher laser power and scanning speed produce the curves of the load vs. displacement characterized by higher values of the resistant load which reaches, in the best case, $90 \mathrm{~N}$. The elongations at break are, in all cases, very low, with the fracture of the joint that appears for elongations, generally, less than $0.1 \mathrm{~mm}$. In this scenario, a determining factor in the formation of the welded joints is certainly the thickness of the PP film. The PP film is $1100 \mu \mathrm{m}$ thick, which is over an order of magnitude more than the thicknesses of the PP films taken into consideration during the tests carried out in the first and second scenarios. During the joining process with the high-power diode laser, only the lower part of the transparent PP film can melt by conduction in contact with the aluminum and take part in the joint formation process. In fact, the PP is

Page 12/32 
transparent to laser radiation and its heating, as will be better discussed later in this work, occurs essentially by heating conduction from the interface with aluminum, which, as a metal material, very effectively absorbs the laser radiation itself. Basically, the joint that forms is too unstable in relation to the thicknesses of the PP films involved in the laser welding process. During the tensile test, the PP film, being $1100 \mu \mathrm{m}$ thick, fails to go into the plastic field before the welded joint fails. For this reason, even very modest elongations cause the joint to break, which, therefore, exhibits a rigid, perfectly elastic behavior. Basically, no form of elongation of the plastic film is observed during the tensile test. The joint between the two materials fails directly, without any deformation in the plastic field being shown in advance either in the metal film or in the film in polymeric material, this being in agreement with the results reported in (Hasegawa, 2017), (van Melick, 2003).

Figure 13 shows the $3 \mathrm{~d}$ map of the maximum load of the load vs. displacement curves measured in tensile tests for welded joints made with the Al $150 \mu \mathrm{m}$ - PP transparent $1100 \mu \mathrm{m}$ assemblies. The whole significant range of the operational parameters was explored. In fact, the combination of scan speed and laser power that lead to satisfactory joining were fully identified. Moving outside the explored range would mean working with a fluence delivered towards the surface that is too much low or high, therefore leading to ineffective welding or to polymer/lacquer degradation. Therefore, at low beam powers and high scanning speeds, the joint does not form and the joint resistance is consequently zero (Wang X. G., 2016). In this case, the power density radiated on the joint surface is not able to trigger the melting of the polymer at the interface with the metal. For this reason, the joint between the two materials does not form or is weakly formed. Similarly, at high beam power and at low scanning speed, the degradation

phenomena of the organic part of the assembly determine the absence of the joint formation, as shown, in some examples, in Figure 14. Substantially, the melting of the material polymer occurs too violently, in the presence of too much energy radiated on the surface of the joint. In the presence of an excessive amount of heat, the vaporized polymer at the interface with the metal tends to form large gas bubbles at the interface.

Such bubbles prevent the joint from forming, rather than favoring it as is normally expected in the transmission laser welding mechanism in agreement with (Wang X. G., 2016), (Gisario A. V., 2017). Again, the strength of the welded joint is zero. High beam powers combined with high scanning speeds or low beam powers combined with low scanning speeds lead to the formation of a stronger joint. As previously stated, for comparable fluence radiated towards the joint surface of the assembly, the joining tests that are characterized by shorter beam-material interaction times allow to obtain the highest strengths of the joint.

\subsection{Analysis of the joining mechanisms}

Laser welding between polymer/metal or different polymers takes place through the LAMP(LaserAssisted Metal and Plastic) joining mechanisms, elsewhere described in (Katayama \& Kawahito, 2008) for a different experimental set-up. This mechanism, of which a schematic representation is built in Figure 15 for the specific case, provides that the interface between two different materials, for example coated metal (i.e., aluminum coated with the lacquer) - polymer (i.e., polypropylene film), is heated by the 
incident laser beam, so as to reach the melting temperature of the plastic material in a limited region near the interface. In this specific case, the material that melts depends on the configuration of the assembly. If the topmost PP film is white. It can absorb a significant share of the laser radiation, thus melting, eventually vaporizing and contributing to the formation of the joint with the underlying coated aluminum. In contrast, if the topmost PP film is completely transparent, it is not able to absorb the laser radiation. In this case, the laser radiation gets all through the thickness of the PP to act at the true interface with the aluminum. In this case, the heat-sealing lacquer, placed at the interface between the metal and the polymer, melts, thus contributing to the establishment of the joint. The lacquer is, in fact, low-melting and is in direct contact with the surface of the aluminum which absorbs most of the laser radiation that gets through the transparent PP film in the assembly. In this area, the high temperatures that are generated at the interface with the aluminum cause the lacquer to melt, vaporize and, consequently, generate gas bubbles that, spreading in the liquid phase, increase the size of the weld bead. The rapid expansion of the gas bubbles generates a high pressure that favors the joint of the coated metal with the polymer. The molten lacquer can penetrate into the morphological profile of the underlying metal or of the polymer above it, also filling the cavities that can be present among them (Figure 15). The vaporization of the lacquer allows it to completely fill the gaps existing between the aluminum surface and the lacquer, which are formed during the coating process with the automatic applicator. Under the action of the advancing blade, the lacquer is not able to completely fill all the gaps in the morphology of the aluminum surface, because of the limited surface wettability. This result is, instead, achievable during laser welding, as the pressure exerted by the gas bubble in the vaporized lacquer facilitates the penetration of the lacquer in the aluminum as well as the welding between the lacquer and the overlying PP film in agreement with (Katayama \& Kawahito, 2008). In the case of transparent PP, laser transmission welding does not involve, therefore, significant morphological alterations of the PP, which is, otherwise, expected to be more susceptible to thermal degradation caused by the irradiation of the laser beam. However, in both the mentioned joint mechanisms (transparent or white PP), the interfacial joining is obtained, thanks to the combined effect of the chemical bonds that are formed between the functional groups present in the lacquer (i.e., mostly vinylic) that coats the metal and in the PP and of the physical bonds resulting from the hydrogen bonds and the Van der Waals forces generated at the interface between the two materials. This is, therefore, the main difference with the typical LAMP mechanism, as the chemical composition of the lacquer can activate both the formation of chemical (primary) bonds at the interface as well as physical bonds, that otherwise could not be formed in case of direct metal/polymer joining. A further mechanism that promotes the formation of the welded joint is, obviously, the effect of mechanical anchoring between the two materials (mechanical interlocking), according to what is reported in (Myer \& Lavigne, 2005). The characteristic phenomena that occur during the welding process require the so-called welding configuration with overlapping edges. Due to the low thermal conductivity of the plastic, the heat remains concentrated at the interface between the coated aluminum and the PP. The amount of heat delivered is a function of the optical properties of the PP. In the case of welding between metal and transparent polymer with laser radiation, the welding takes place only if the absorption of the beam is concentrated at the true interface between the two materials to be joined. Since the joint interface is made up of surfaces of different materials, most of the absorption in the weld occurs here, especially if the 
organic counterparts allow the laser beam to be transmitted. This process is therefore suitable for joining with thermoplastic materials without the need to use additives or dyes to improve the absorption of the beam in agreement with the results reported in (Moskvitin, Polyakov, \& Birger, 2013). Lastly, the role of surface asperities and metal oxides are in this case very limited because of the application of the organic resin (i.e. the lacquer) on the aluminum surface and the shield gas used during the laser irradiation. The resin surface is always very smooth, as seen before. It also isolates the aluminum surface preventing any form of oxidation. As said, joining is also operated under a shield gas to prevent further any source of metal oxidation.

\subsection{Analysis of the peel-off tests}

Figure 16 shows the trend of the peel-off curves on the Al $50 \mu \mathrm{m}$ - white PP $80 \mu \mathrm{m}$ joints, which allow to evaluate the adhesion strength of the aluminum - polymer joints subjected to the action of a load placed at $90^{\circ}$ with respect to the lying of the joint. The tear resistance is highly variable according to the setting of the beam power and the scanning speed in agreement with (Vogel, 2011). In particular, the joints performed at higher power showed greater tear strength. In any case, the tear strength does not exceed 10 $\mathrm{N}$. The tear strength is approximately one order of magnitude lower than the corresponding weld joint strength measured by the previous tensile test. The evaluation of the area underlying the load vs. displacement curve in the peel-off test allows to obtain an estimate of the work (i.e., tear energy) required to complete the detachment of the two parts of the joint. From Figure 16, the work required to achieve complete fracture of the welded joint tends to increase for higher values of beam power and scanning speed. The fracture of the welded joint, as aforesaid, always occurs due to the defibration of the edge of the polymeric part of the assembly. This occurs precisely due to the effect of the polymer stretching mechanism during the static test, but also through the crazing mechanism (Ge \& Robbins, 2014), quite common in polymers and which regulates the formation of the fracture inside them. Basically, the polymeric materials subjected to an oriented load show, in turn, a corresponding orientation of the polymer chains. This orientation may or may not be accompanied by a crazing phenomenon, prior to the formation of the complete fracture in the material. In the event that the crazing phenomenon is manifested vigorously, vacuum zones begin to form inside the polymeric material, interspersed with the formation of fibrillar bridges consisting of highly oriented polymer chains. In correspondence with the latter, a strong localization of the plastic deformation occurs. In the presence of the crazing phenomenon, the polymeric material can, therefore, exhibit a strong increase in tear resistance, which is very common in the case of welded joints made of homogeneous and miscible polymeric materials (in this case, the extent of the phenomenon of crazing is to be ascribed to the affinity or miscibility of the resin used for the coating and the polymeric material, i.e. PP) (Ge \& Robbins, 2014). For inhomogeneous materials (immiscible or partially miscible), the phenomenon of crazing is, in general, less marked, predominating, as failure mechanism, that of elongation and defibration of the polymer chains, subjected to the load. In this case, the tear strength is generally expected to be lower than in the previous case (in which the crazing phenomenon is more apparent) (Ge \& Robbins, 2014). 
Figure 17, on the other hand, shows the trend of the peel-off curves on the welds Al $50 \mu \mathrm{m}$ - PP $80 \mu \mathrm{m}$ transparent. Again, transparent PP exhibits a different behavior from white PP. The curves, while maintaining that characteristic jagged trend, show on average higher loads and smaller displacements in analogy to what was observed in the previous tensile tests.

The peel-off test was not carried out on the transparent Al $50 \mu \mathrm{m}$ - PP $1100 \mu \mathrm{m}$ welds, as the same, even in the tensile test, exhibited an excessively rigid and perfectly plastic behavior. Consequently, the preliminary tests showed the inadequacy of the experimental configuration chosen in the peel-off test.

Finally, Figure 18 shows the trend of the area under the load vs. displacement of peel-off tests for aluminum films coupled with white (Figure 18a) and transparent (Figure 18b) PP. The higher areas, corresponding to higher energy levels needed to tear the joint in peel-off tests, always occur for higher laser beam powers and scanning speeds, for all scenarios examined, thus confirming the better suitability of laser transmission welding of polymers with metals operated with lower interaction time of the laser beam with the welded joint (Wang X. G., 2016), (Gisario A. V., 2017).

\section{Conclusions}

The present work concerns the study of welded joints between aluminum and PP films, materials commonly used for food packaging. Based on the experimental findings, the following pointwise conclusions can be drawn:

- all the joints between aluminum and PP are obtained through the so-called Laser Transmission Welding (LTW) mechanism, this despite the difference in color or thickness of the substrates, this being favored by the coating of the aluminum with the thermo-sealable lacquer;

- the joint between the two materials consists of chemical bonds between related functional groups (i.e., vinylic) in the polymer and on the coated aluminum surface, physical interactions (i.e., hydrogen bonds and van der Waals forces) that regulate the interaction between the two materials at the interface and mechanical interlocking (i.e., interpenetration of the two materials in the morphological asperities at the interface);

- the thickness of the films, their ability to interact with the laser beam (i.e., the absorption of the laser radiation), the levels of fluence set and the interaction times between beam and material are the factors controlling the process;

- the experimental results allowed to identify the optimal processing window, that is, the choice of the operational parameters that leads to satisfactory welded joints.

In conclusion, the present study allowed to increase the knowledge on welding of dissimilar materials, with particular focus on polypropylene and aluminum films, both broadly used in the manufacturing of food and beverage packaging solutions. In particular, the experimental findings allowed to emphasize that the main difference with the typical laser welding mechanism is the formation of primary and secondary bonds at the interface. This can be ascribed to the chemical composition of the lacquer that 
can activate both the formation of chemical bonds at the interface as well as physical bonds, that otherwise could not be formed in case of direct metal/polymer joining. Laser was found to be a viable solutions for welding polypropylene and aluminum films, thus proposing it as an effective and safe alternative to the current welding process.

\section{Statements}

The authors declare that no funds, grants, or other support were received during the preparation of this manuscript.

The authors have no relevant financial or non-financial interests to disclose.

Data will be made available on reasonable request.

Code availability: not applicable

No ethical approval is required.

Consent to participate: not applicable

Consent to publish: not applicable

The contribution of the authors to the study conception, design, material preparation, data collection and analysis is equal. The first draft of the manuscript was written by prof. Annamaria Gisario. Prof. Massimiliano Barletta revised the manuscript. All authors read and approved the final manuscript.

\section{Declarations}

\section{Acknowledgements}

Interns at Manufacturing Engineering of Department of Mechanical and Aerospace Engineering of Sapienza University of Rome, is kindly acknowledged for his contribution to the development of the experimental tests. Mr. Andrea Brotzu, technician at the same Department, is kindly acknowledged for the development of the peel-off test apparatus. The authors would also like to acknowledge the economic support received from the research project "Smart Aluminium per imballaggi intelligenti nel settore alimentare e farmaceutico" developed within the Azione 3.3.1 sub-azione - "Riposizionamento competitivo di sistemi e filiere produttive"; - Asse prioritario 3 - Competitività "Call for Proposal" supported with the D.D. n. G03561 of Regione Lazio on 11 April 2016.

\section{References}

1. Acherjee B (2020) Laser transmission welding of polymers - A review on process fundamentals, material attributes, weldability, and welding techniques. J Manuf Process 60:227-246 
2. Acherjee B, Maity DK (2017) Parameters optimisation of transmission laser welding of dissimilar plastics using RSM and flower pollination algorithm integrated approach. Int J Math Model Numer Optim 8(1):1-22

3. Amanat NJ (2010) Welding methods for joining thermoplastic polymers for the hermetic enclosure of medical devices. Med Eng Phys 32:690-699

4. Askadskii A, Matseevich T, Popova M, Kondrashchenko V (2015) Prediction of the compatibility of polymers and analysis of the microphase compositions and some properties of blends. Polym Sci Ser A 57(2):186-189

5. Banks WA, Kastin AJ (1989) Aluminium-induced neuro-toxicity: alterations in membrane function at the blood-brain barrier. Neurosci Biobehav Rev 13:47-55

6. Barletta MG (2006) Advance in paint stripping of aluminum substrates. 173:232-2392

7. Bodzay BM (2009) Polymer degradation studies using laser pyrolysis FTIR micro analysis. J Anal Appl Pyrol 85(1):313-320

8. Brown N, Kerr D, Jackson M, \& R.M., P (2000) Laser welding of thin polymer films to container substrates for aseptic packaging. Opt Laser Technol 32:139-146

9. Brown N, Kerr D, Parkin R, Jackson MS (2012) Non-contact laser sealing of thin polyester food packaging films. Opt Lasers Eng 50:1466-1473

10. Brown N, Shi F, Jackson MP (2005) CO2 laser processing of multilayer packaging films. Proceedings of IMechE: Journal of Systems and Control Engineering, 219(Part I), 231-237

11. Brown N, Shi F, Kerr D, Jackson M, Parkin R (2003) CO2 laser processing of packaging films including multi-layer laminates containing silicon oxide and ethylenevinyl alcohol barrier layers. Proceedings of the international conference on mechatronics (ICOM) (pp. 383-388). Loughborough: Professional Engineering Publishing

12. Brunnecker F (2018) Welding of radially symmetrical plastic parts. Optik \& Photonik 4:96-98. Retrieved from www.photonicsview.com

13. Falk ST (2018) Evaluation of human exposure to aluminum from food and food contact materials. Eur Food Res Technol 244(12):2077-2084

14. Fiorini M, Campana G, Pagano N, Morelli R (2015) Comparison between joining technologies for polymeric films. Procedia CIRP 33:412-417

15. Ge TG, Robbins M (2014) Tensile Fracture of Welded Polymer Interfaces: Miscibility, Entanglements, and Crazing. Macromolecules 47(19):6982-6989

16. Ghasemi HZ (2018) Effect of processing parameters on meltdown in qausi-simultaneous laser transmissione welding. Opt Laser Technol 107:244-252

17. Ghorbel EC (2009) Laser diode transmission welding of polypropylene: geometrical and microstructure chracterisation of weld. Mater Des 30:2745-2751

18. Gisario AM (2017) Dissimilar joining of trasparent Poly(ethylene terephtalate) to aluminum 7075 sheets using a diode laser. Journal of Laser Applications, 29(022418) 
19. Gisario AV (2017) Laser transmissione welding of poly(ethylene terephtalate) and biodegradable poly(ethylene terephtale) - based blends. Opt Lasers Eng 90:110-118

20. Grewell DB (2013) Medical Engineering \& Physics. Int Polym Proc 22(1):43-60

21. Gupta VS (2005) Aluminium in Alzheimer's disease: Are we still at a crossroad? Cellular and Molecular Life Sciences CMLS 62(2):143-158

22. Hasegawa HO (2017) Stress-strain measurement of ultra-thin polystyrene films: Film thickness and molecular weight dependence of crazing stress. Polymer (Guilford) 123:179-183

23. Ilie MS (2020) Experimental design investigation of through transmission laser welding of dissimilar polymers.J Phys Conf Ser, 1426(012045)

24. Jones I (2016) Laser welding plastics. Great Abington, Cambridge, Uk: TWI Ltd. Retrieved from https://www.twi-global.com/pdfs/Events/lan-Jones-Laser-welding-plastics.pdf

25. Kang MJ (2018) Tensile-Shear Fracture Behavior Prediction of High-Strength Steel Laser Overlap Welds. Metals 8(5):365

26. Katayama S, Kawahito Y (2008) Laser direct joining of metal and plastic. Scripta Mater 59(12):1247-1250

27. Liu M, Ouyang D, Zhao J, Li C, Sun HR (2018) Clear plastic transmission laser welding using a metal absorber. Opt Laser Technol 105:242-248

28. Ljungberg N, Andersson T, Wesslen B (2003) Film extrusion and film weldability of Poly(lactic acid) plasticized with triacetine and tributyl titrate. J Appl Polym Sci 88:3239-3247

29. Mehrpouya MG (2019) An artificial neural netwrok model for laser transmission welding of biodegradable polyethyleneterephthalate/polyethylene vinyl acetate (PET/PEVA) blends. Int J Adv Manuf Technol 102:1497-1507

30. Mingareev IW (2012) Welding of polymers using a 2 micron thulium fiber laser. 44:2095-2099

31. Moskvitin G, Polyakov A, Birger E (2013) Laser welding of plastics. Weld Int 65(9):21-33

32. Myer E, Lavigne G (2005) Adhesion failure of plastic bonded to various materials. Joining of medical plastics conference (pp. 1-8). Providence, RI: SPE - Inspiring Plastics Professionals

33. Najarzadeh Z, Ajji A (2004) A novel approach toward the effect of seal process parameters on final seal strength and microstructure of LLDPE. J Adhes Sci Technol 28(16):1592-1609

34. Navas-Martos FY-R (2018) Laser transmission welding of poly(lactic acid) and polyamide66/sepiolite nanocomposites. 135:4663836

35. Oliveira NP (2014) In mold laser welding for high precision polymer based optical components. AIP Conference Proceedings, 1593, 204-208

36. Pagano N, Campana G, Fiorini M, Morelli R (2017) Laser transmission welding of polylactide to aluminium thin films for applications in the food-packaging industry. Opt Laser Technol 91:80-84

37. Potente HF (2006) An approach to model the melt displacement and temperature profiles during the laser through-transmission welding of thermoplastics. Polym Eng Sci 46:1565-1575 
38. Prabhakaran RK (2006) Contour laser - laser transmission welding of glass reinforced nylon $6 . \mathrm{J}$ Thermoplast Compos Mater 19:427-439

39. Rhew MM (2003) Diode laser chracterization and measurement of optical properties of polycarbonate and high-density polyethylene. Conference proceedings, annual technical conference // ANTEC 2003. 1, pp. 1056 - 1060. Nashville, Tennessee: Society of Plastics Engineers

40. Sproesser G, Chang Y-J, Pittner A, Finkbeiner M, Rethmeier M (2015) Life Cycle Assessment of welding technologies for thick metal plate welds. J Clean Prod 108(Part A):46-53

41. Sproesser G, Chang Y-J, Pittner A, Finkbeiner M, Rethmeier M (2017) Sustainable technologies for thick metal plate welding. Springer, Cham

42. Stokes A, Conway K (2001) A phenomenological study of the hot-tool welding of thermoplastics. 4. Weld strength data for several blends. Polymer 42:7477-7493

43. Tillmann W, Elrefaey A, Wojarski L (2010) Toward process optimization in laser welding of metal to. Materials Science \& Engineering Technology 41(10):879-883

44. van Melick HG (2003) Prediction of brittle-to-ductile transitions in polystyrene. Polymer (Guilford) 44(2):457-465

45. Vogel J (2011) Sealing and cutting of PLA bio-plastic. lowa: lowa State University, 2011

46. Volkov S, Chernyak B (1987) Welding of plastics, a textbook. Khimiya, Moscow, Russia

47. Wang XG (2016) Thermal degradation of PA66 during laser transmission welding. Opt Laser Technol 83:35-42

48. Wang XS (2012) Modeling and optimization of laser transmissione joining process between PET and 316L stainless steel using responsasurface methodology. Opt Laser Technol 44(3):656-663

\section{Figures}




\section{Grid $6 \times 4$}

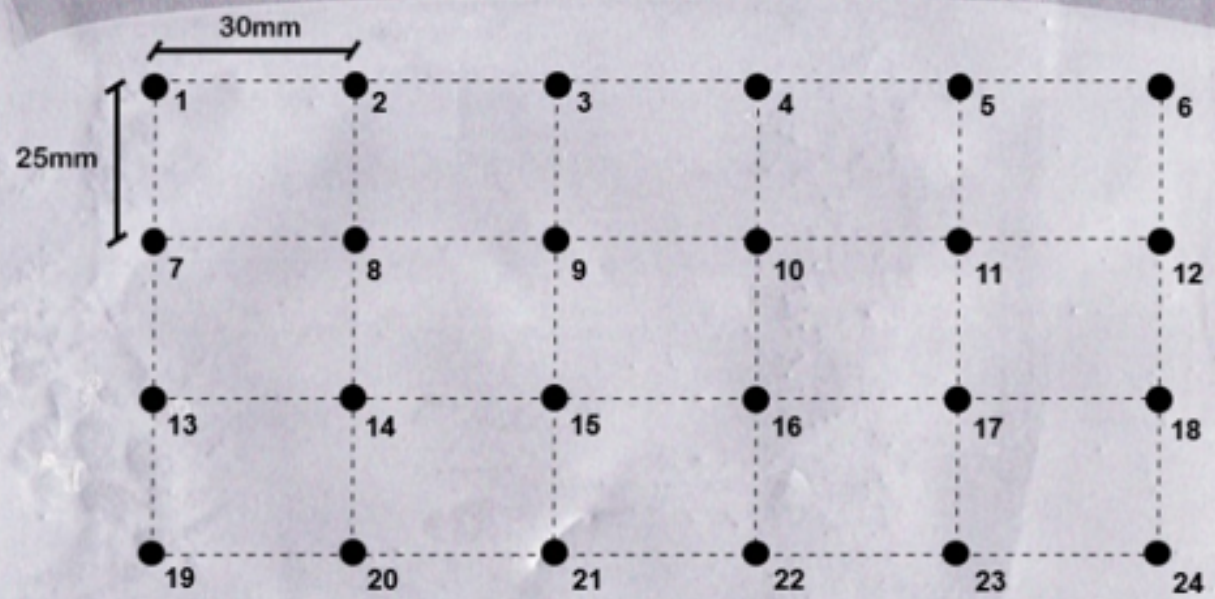

\section{Figure 1}

Measurement of the thickness of the coatings

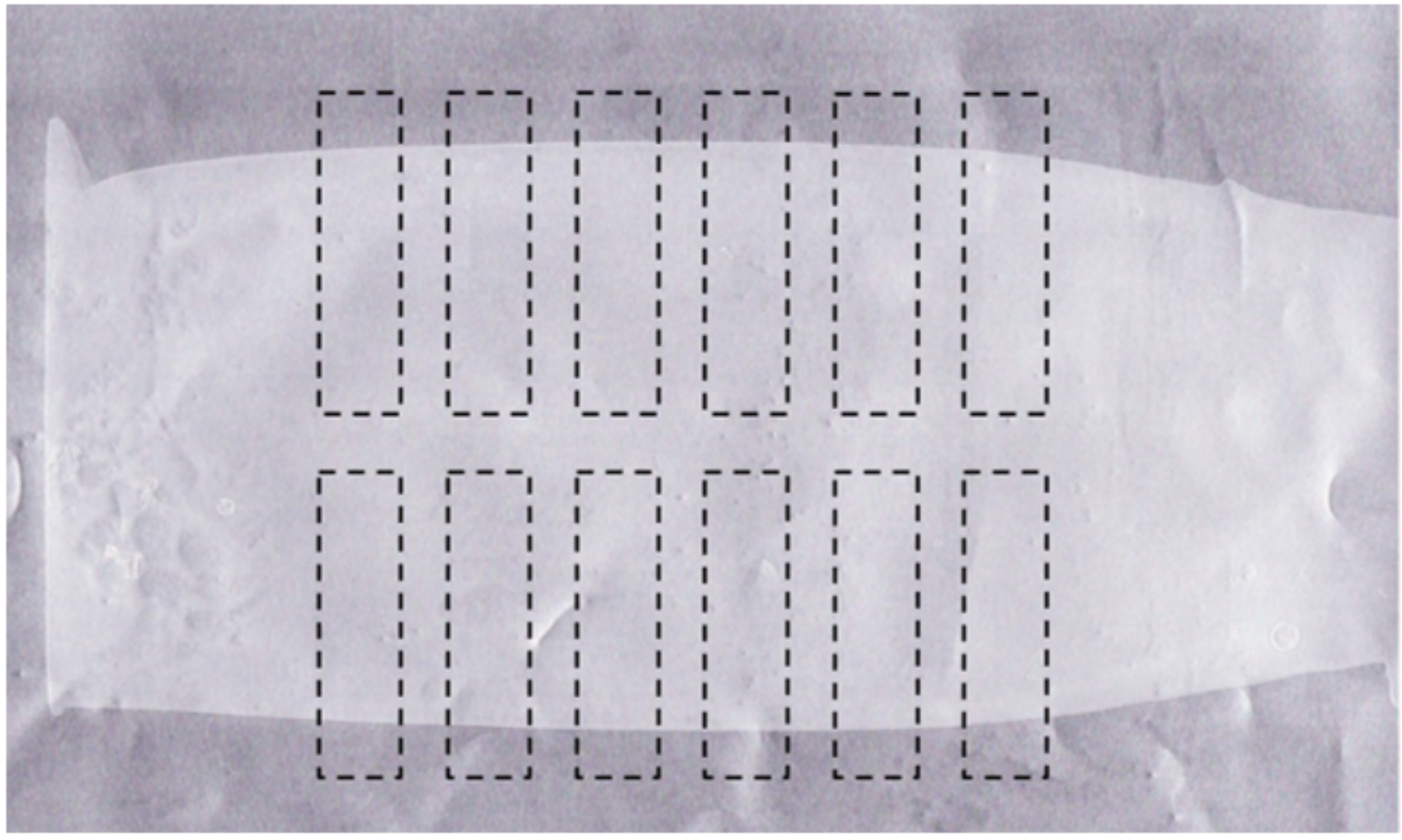

Figure 2

Schematic of the cutting process of the lacquered foils 


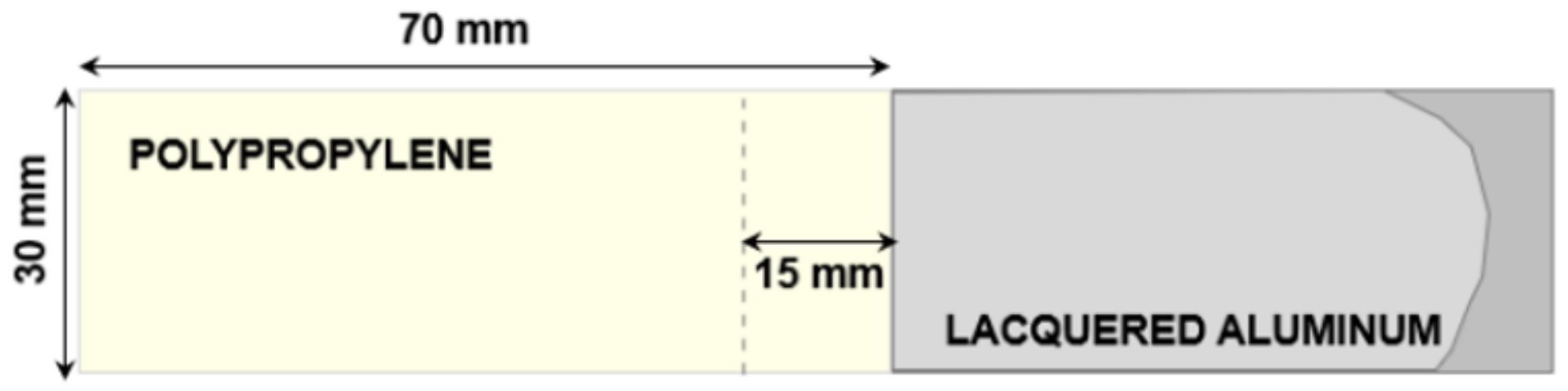

Figure 3

Sample geometry

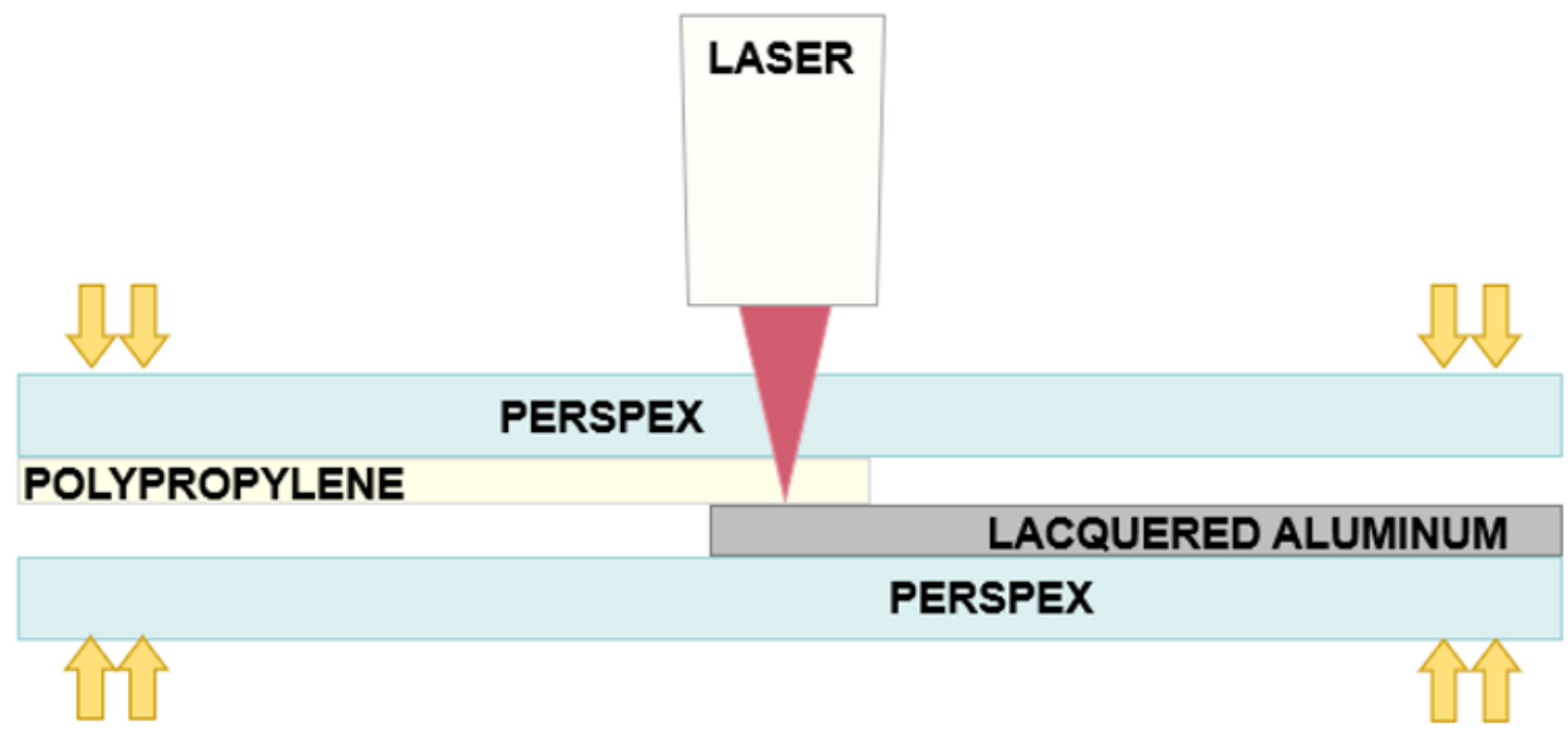

Figure 4

Clamping system used during the laser welding process 

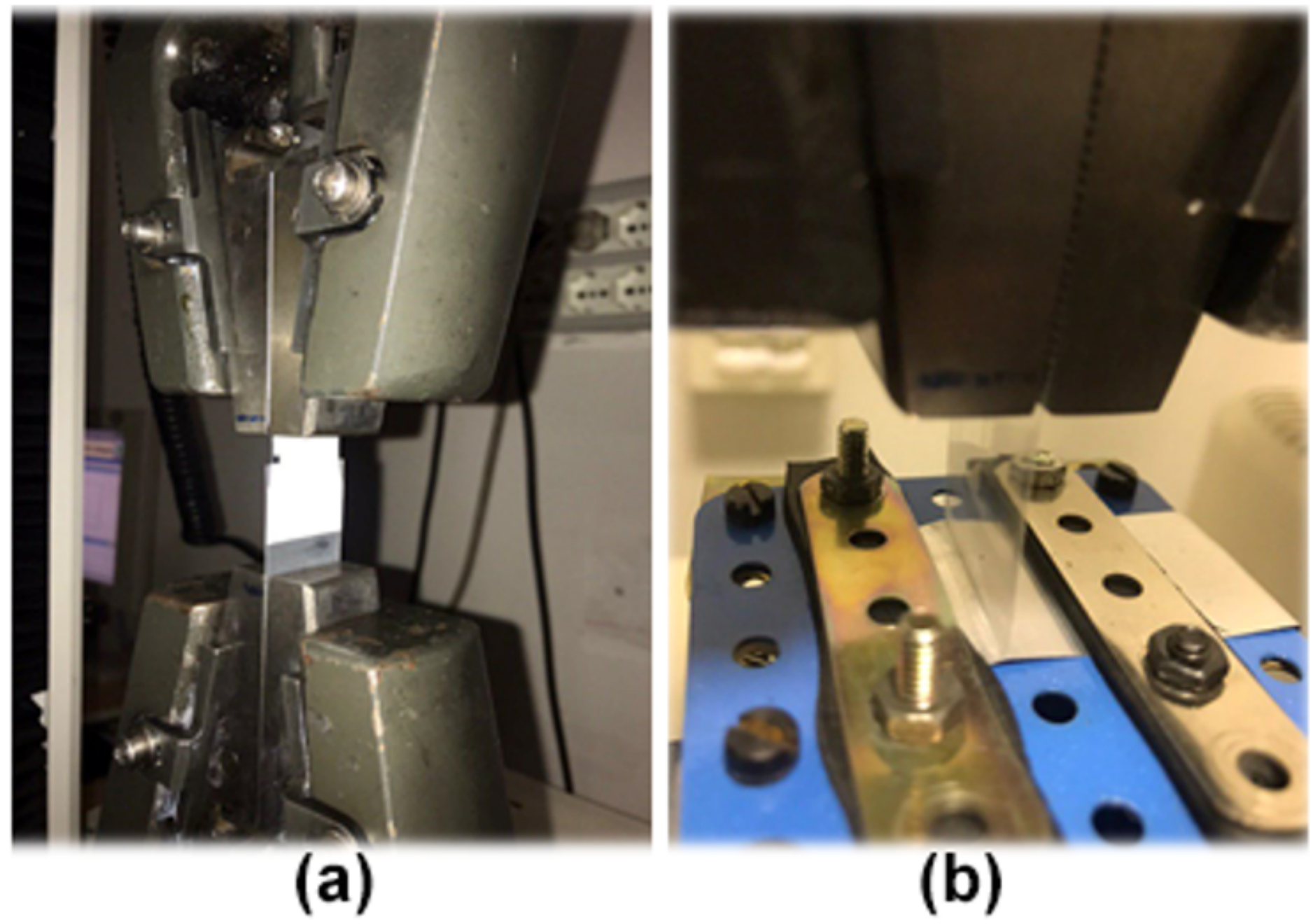

Figure 5

Clamping systems for tensile and peel-off tests: (a) tensile test; (b) peel off test

Figure 6

Trend of resin coating thickness on aluminum substrate (each label refers to the given name of the sampleas specified in Section 2) 


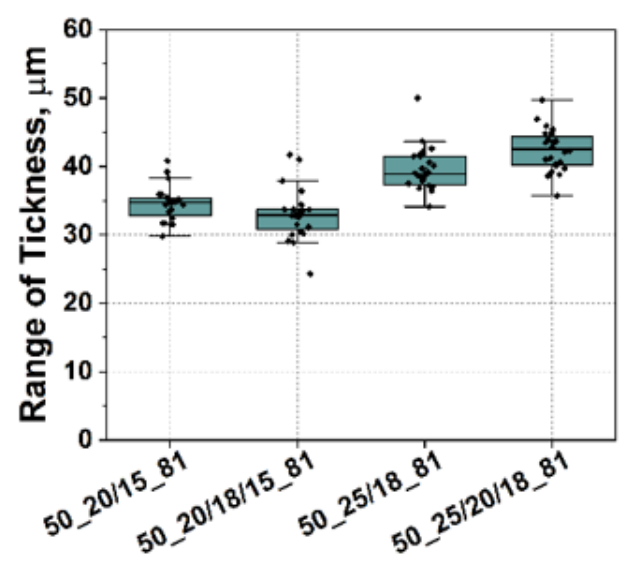

(a)

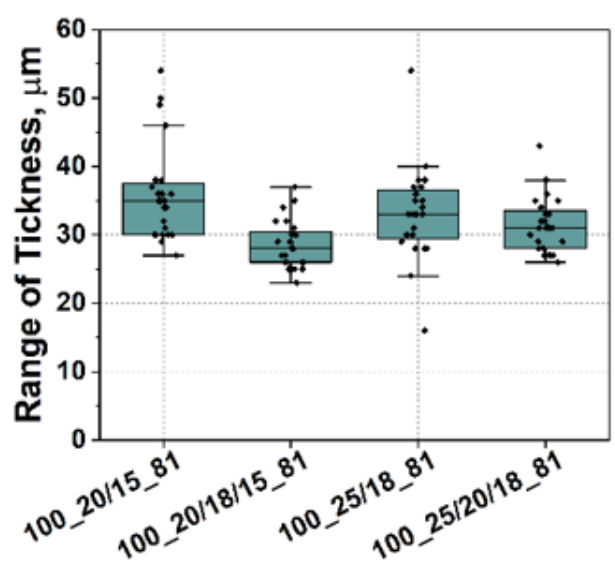

(b)

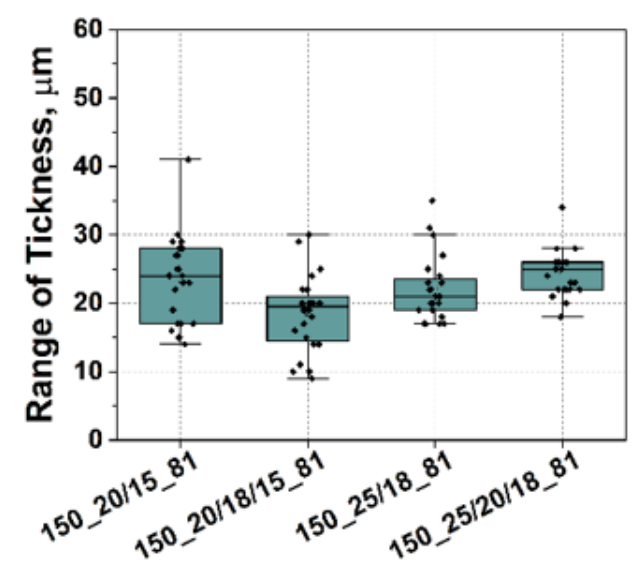

(c)

Figure 7

Box plots of resin coating thickness on aluminum substrates: (a) $50 \mu \mathrm{m}$ thick; (b) $100 \mu \mathrm{m}$ thick; (c) 150 $\mu \mathrm{m}$ thick

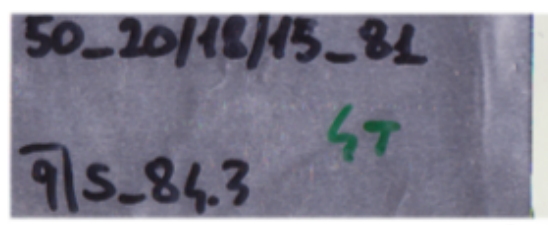

(a)

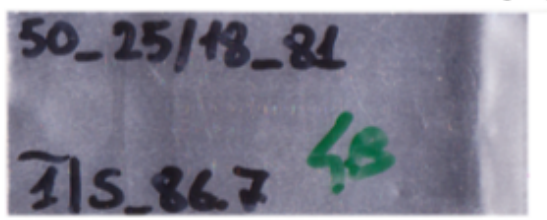

(c)

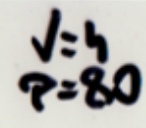

$J=4$
$P=80$

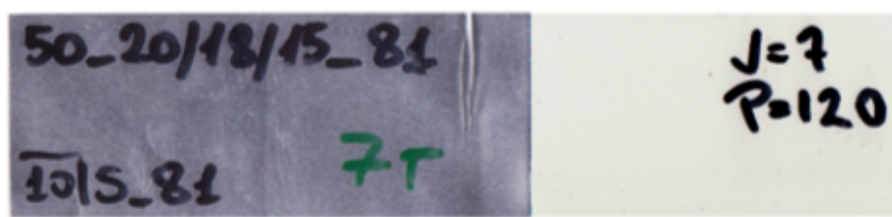

(b)

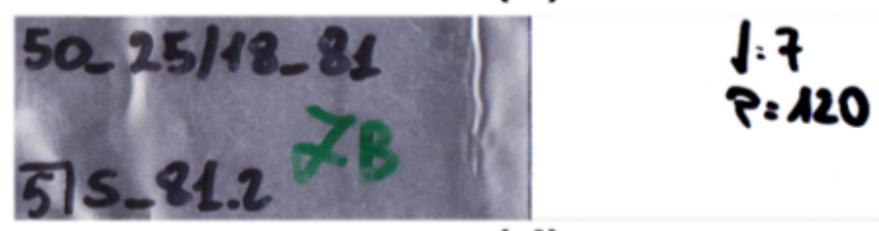

(d)

Figure 8

Laser joints of coated aluminum with PP films (Al $50 \mu \mathrm{m}$ - PP $80 \mu \mathrm{m}$ assembly): (a), (b) white PP; (c), (d) transparent PP 


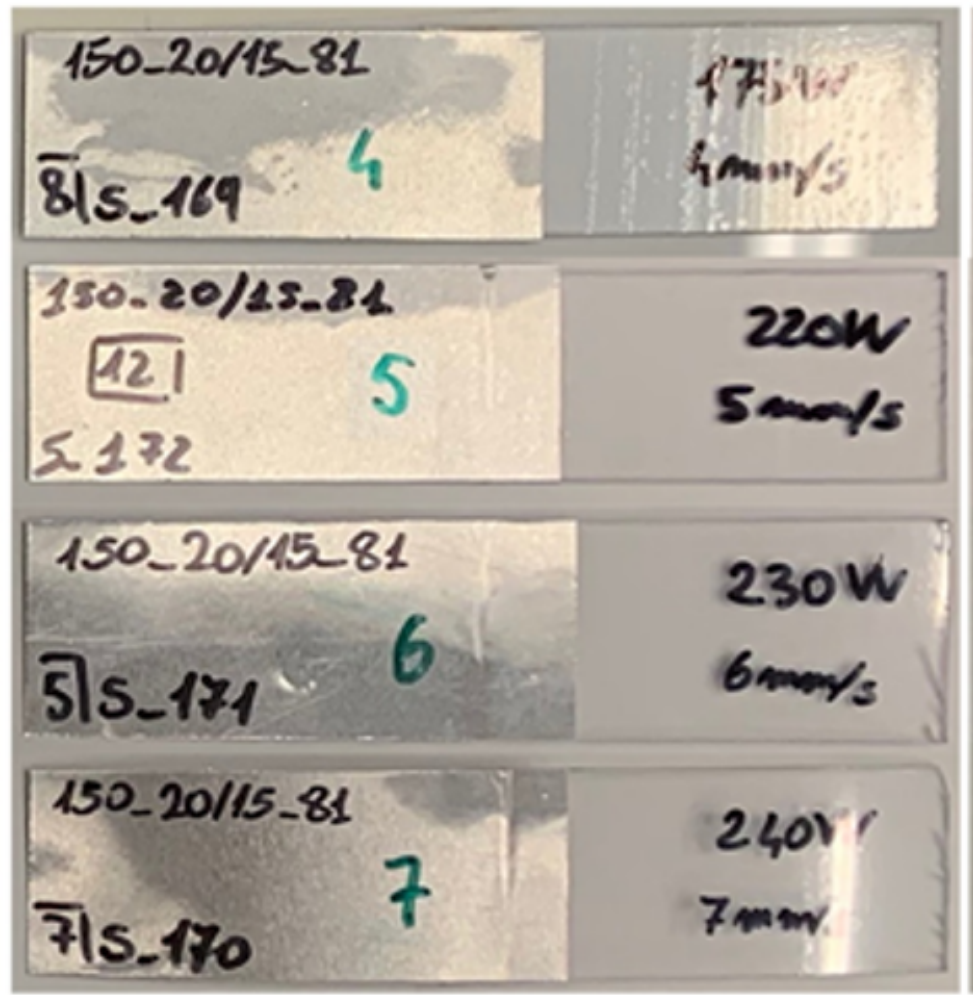

(a)
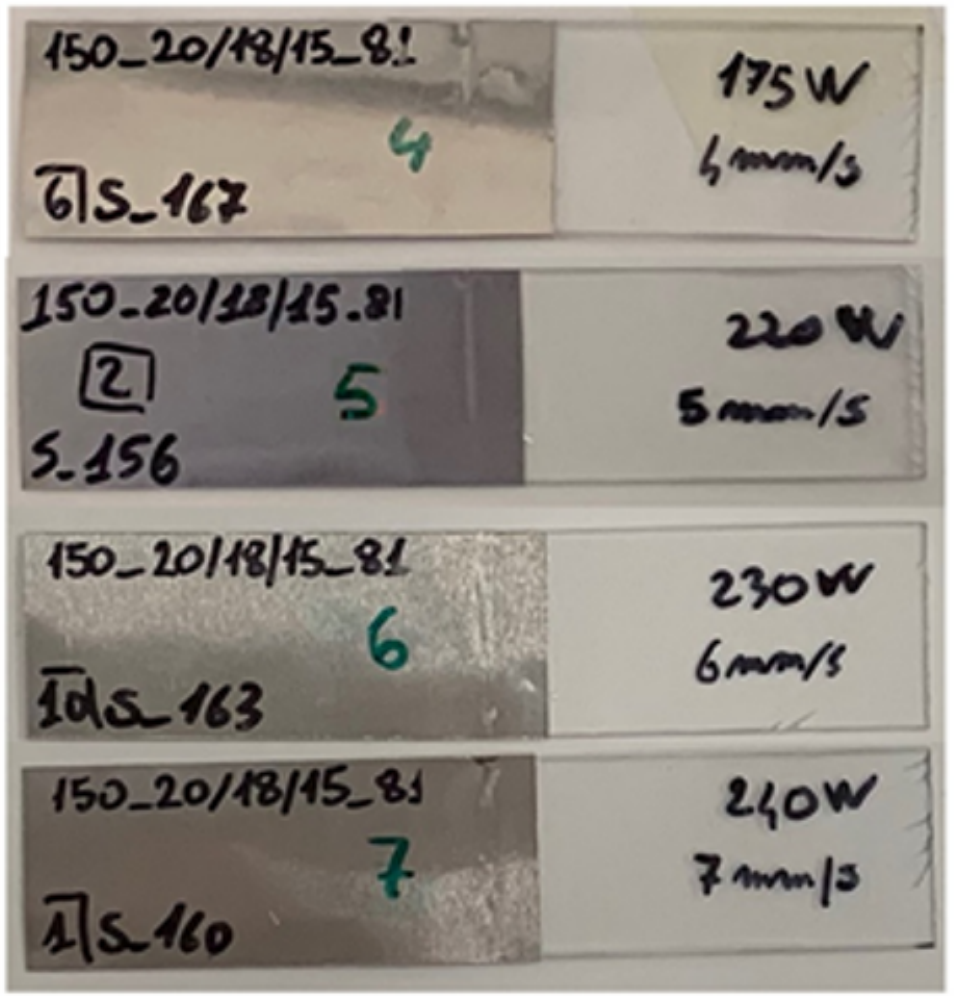

(b)

Figure 9

Laser joints of Al $150 \mu \mathrm{m}$ - PP $1100 \mu \mathrm{m}$ assembly: (a) two lacquering steps; (b) three lacquering steps 

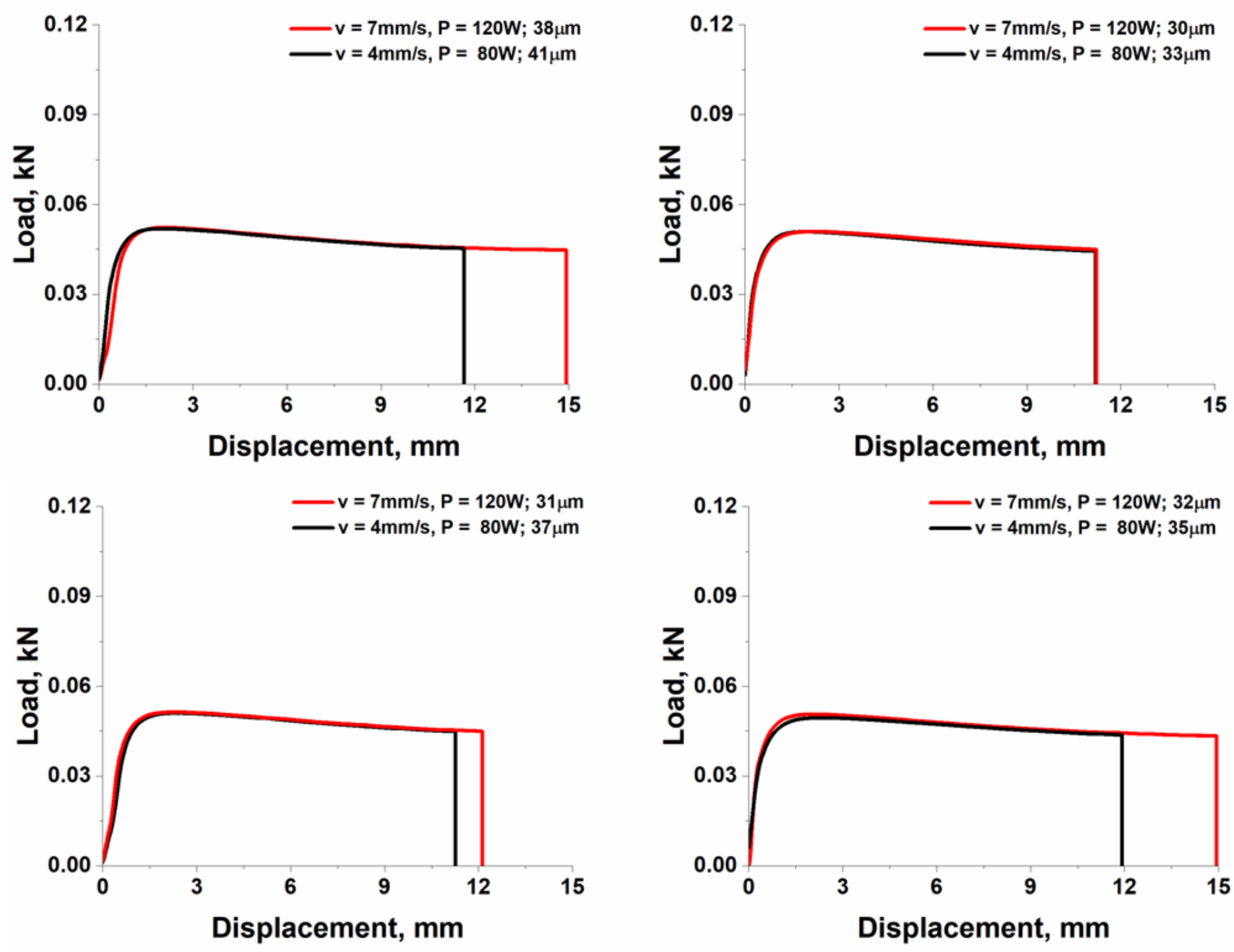

Figure 10

Load - displacement graph for tensile tests on Al $50 \mu \mathrm{m}$-PP $80 \mu \mathrm{m}$ white. 

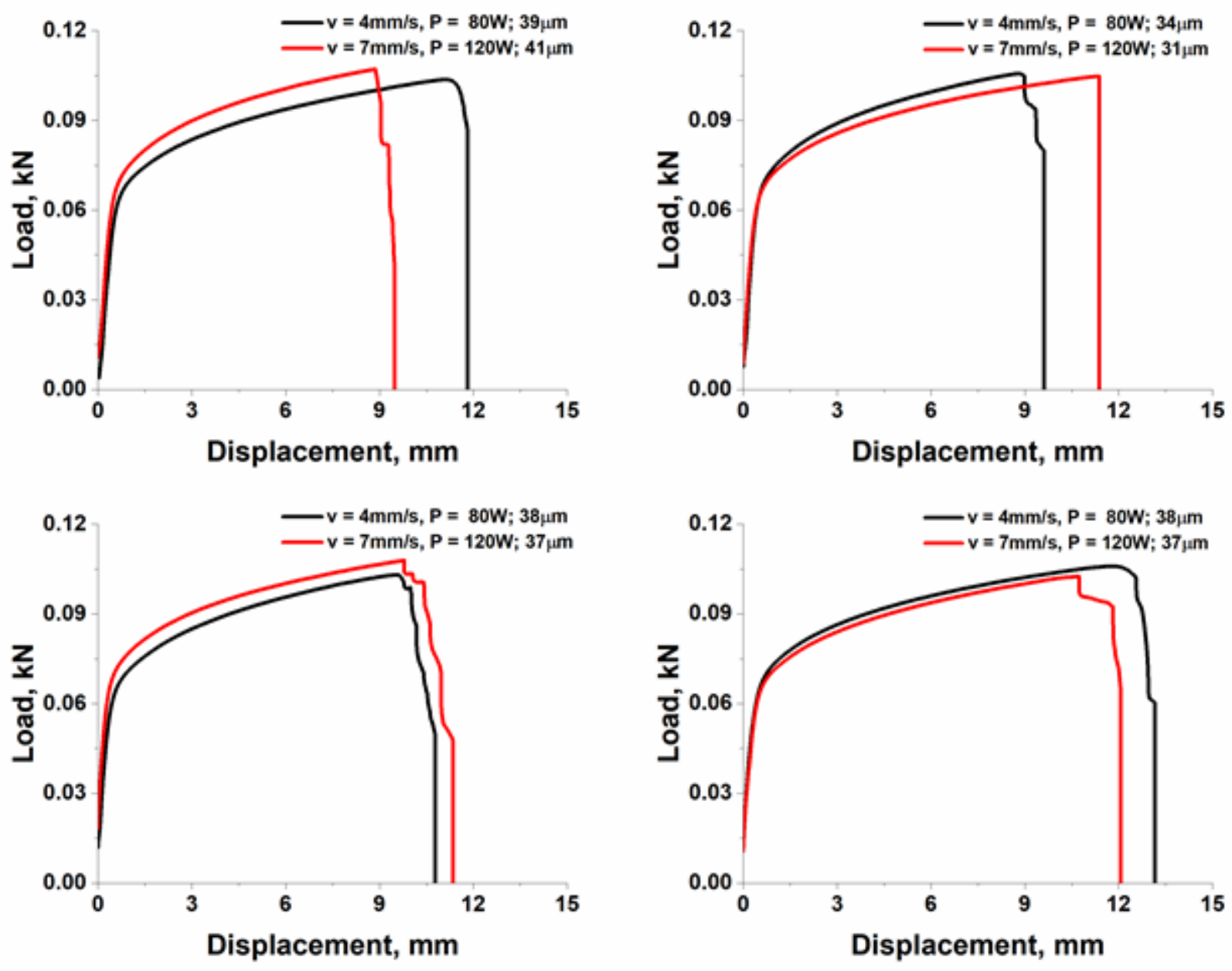

Figure 11

Load - displacement graph for tensile tests on Al $50 \mu \mathrm{m}$-PP $80 \mu \mathrm{m}$ trasparent

$150 \_20 / 15$

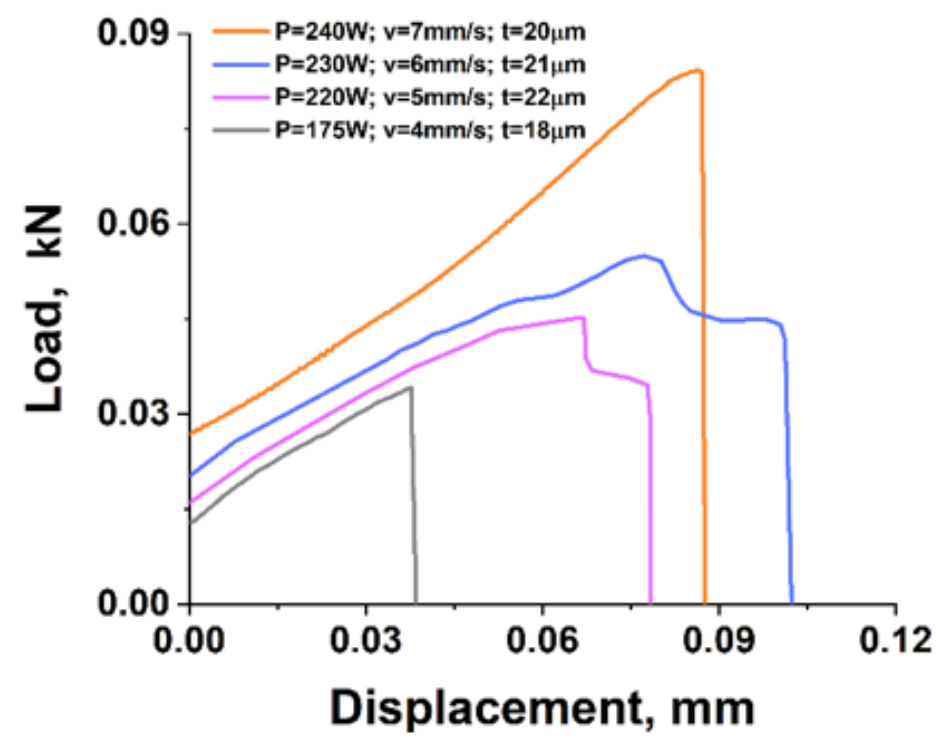

150_20/18/15_81

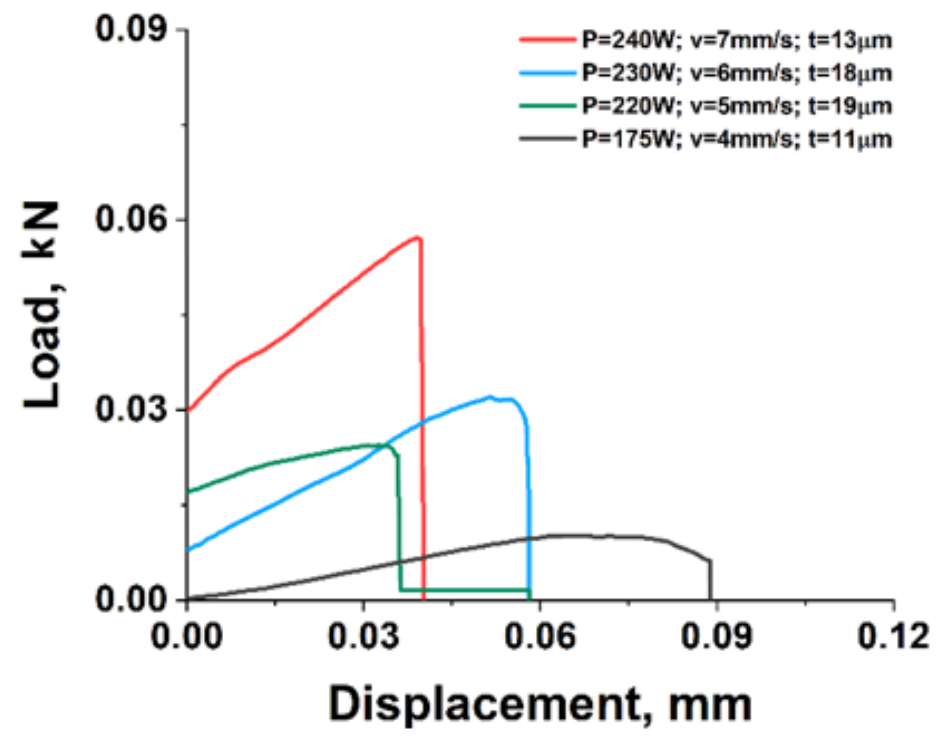

Figure 12 
Trends of the welded joints with Al $150 \mu \mathrm{m}$ - PP $1100 \mu \mathrm{m}$ assembly

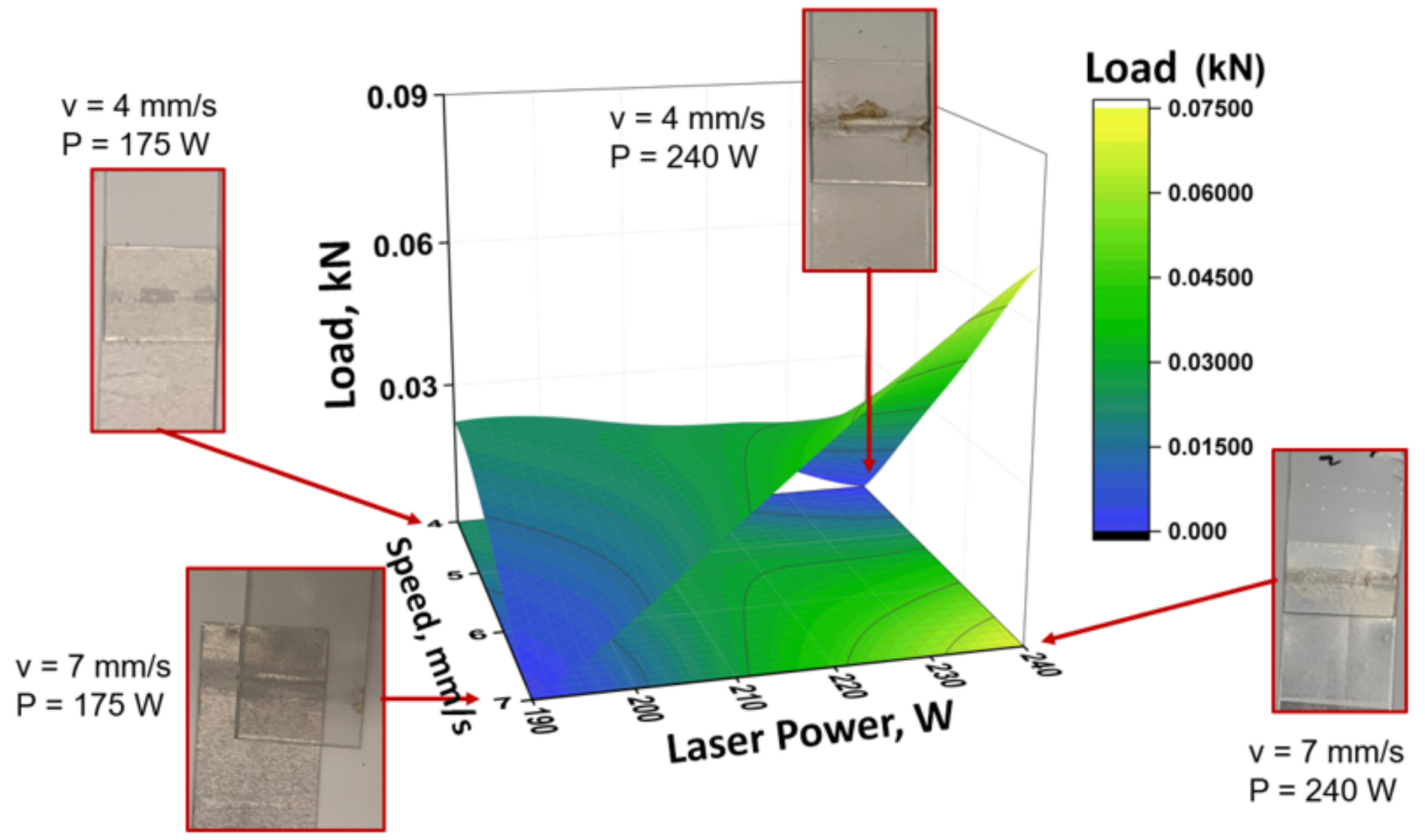

Figure 13

3d map of the welded joint with Al $150 \mu \mathrm{m}$ - PP $1100 \mu \mathrm{m}$ assembly 


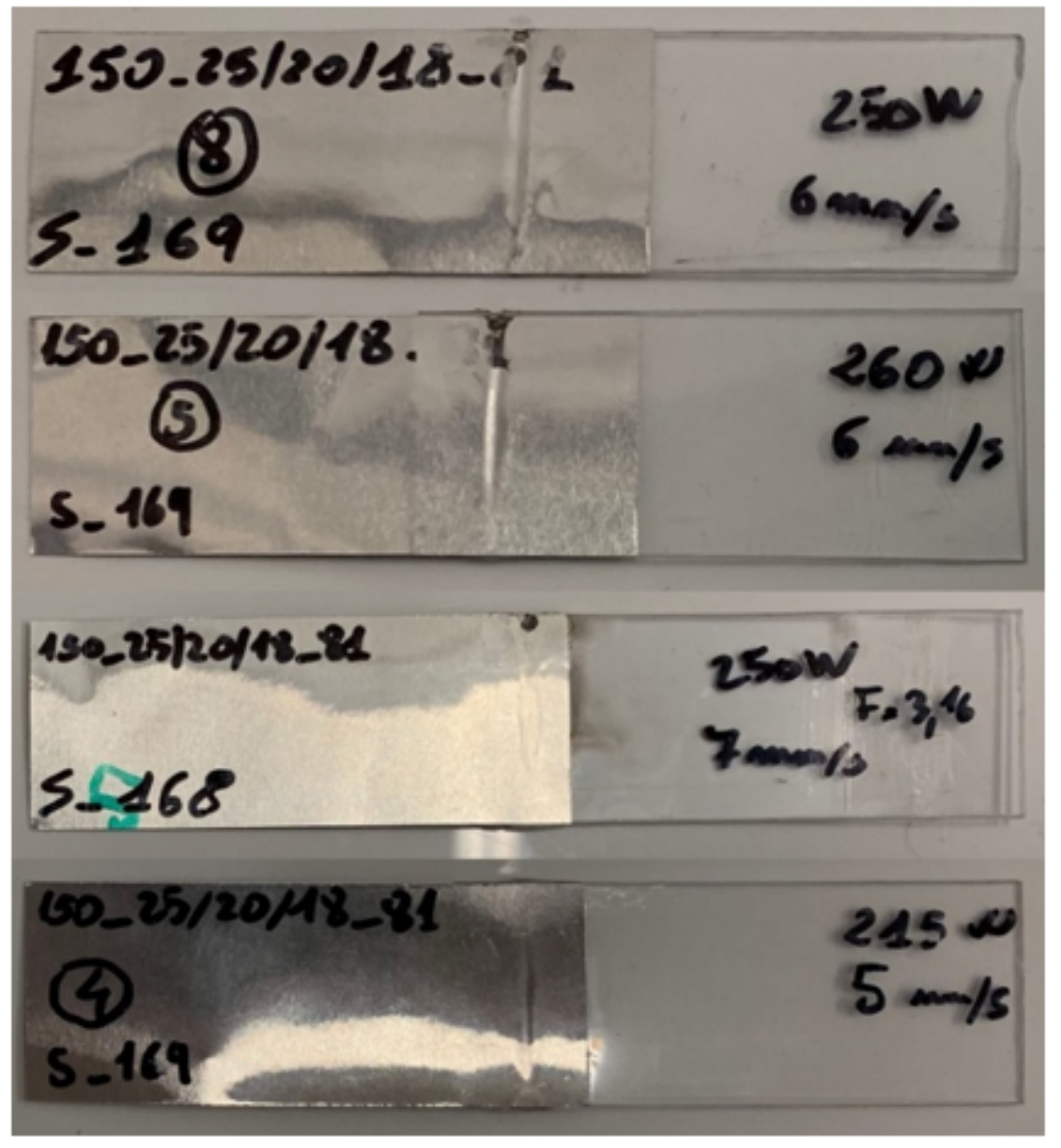

Figure 14

Laser joints of film in Al $150 \mu \mathrm{m}$ - PP $1100 \mu \mathrm{m}$ with incipient degradation phenomena 
(1)

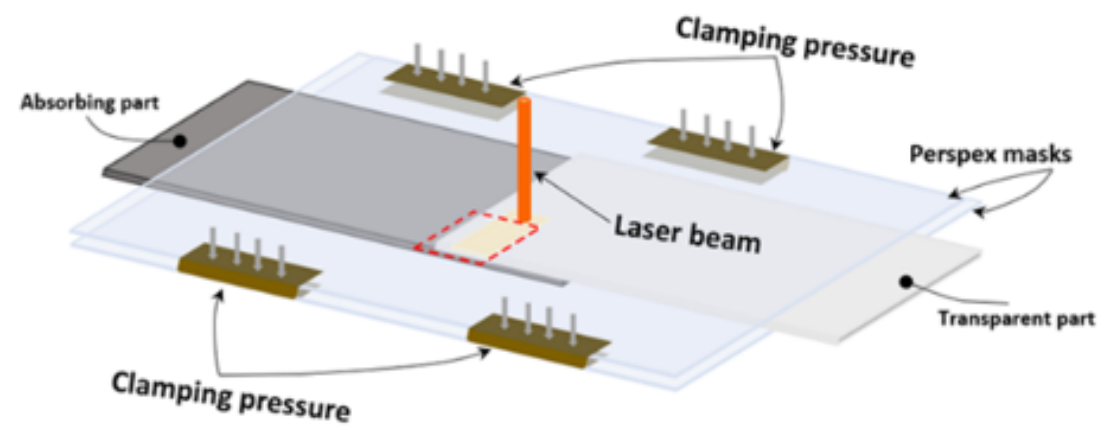

(2)

Polypropylene

Lacquer

\section{Aluminium}

(3)

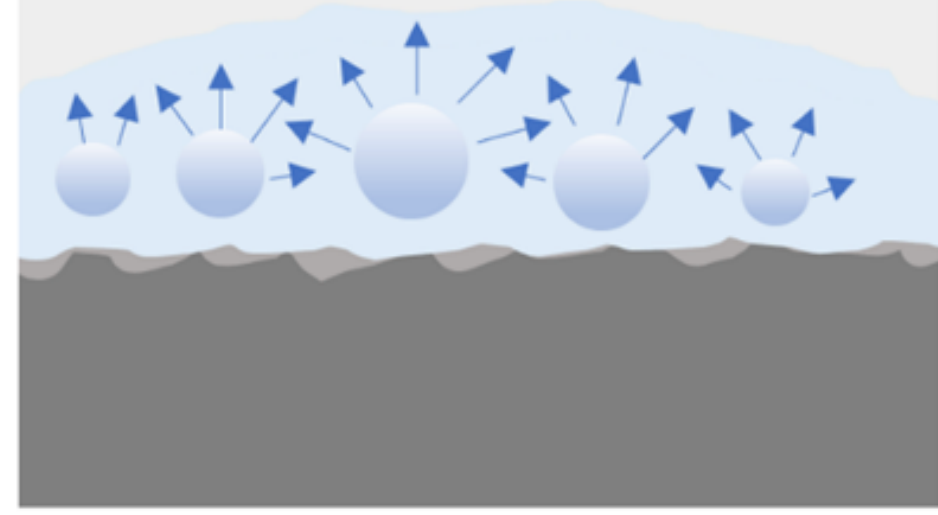

(4)

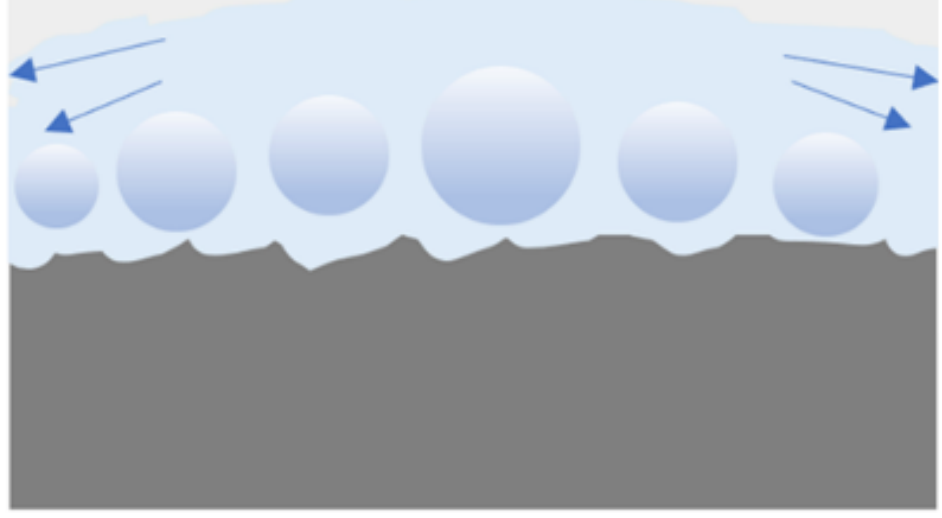

\section{Figure 15}

Mechanisms involved in the laser joining process between different materials: (1) the laser radiation heats the joining area; (2) the heat melts the PP if it is able to absorb a significant share of the laser radiation, otherwise penetrate through the transparent polymers (PP and lacquer) until reaching the true interface with the aluminum; (3) the aluminum Is quickly heated as it absorbs the laser radiation, transferring the heat by conduction to the overlying low melting and heat sealable lacquer, causing it melt and vaporize; (4) the bubble inside the lacquer generates a pressure that forces the lacquer to penetrate inside the gap at the interface with the aluminum and PP, thus generating the formation of the welded joint. 

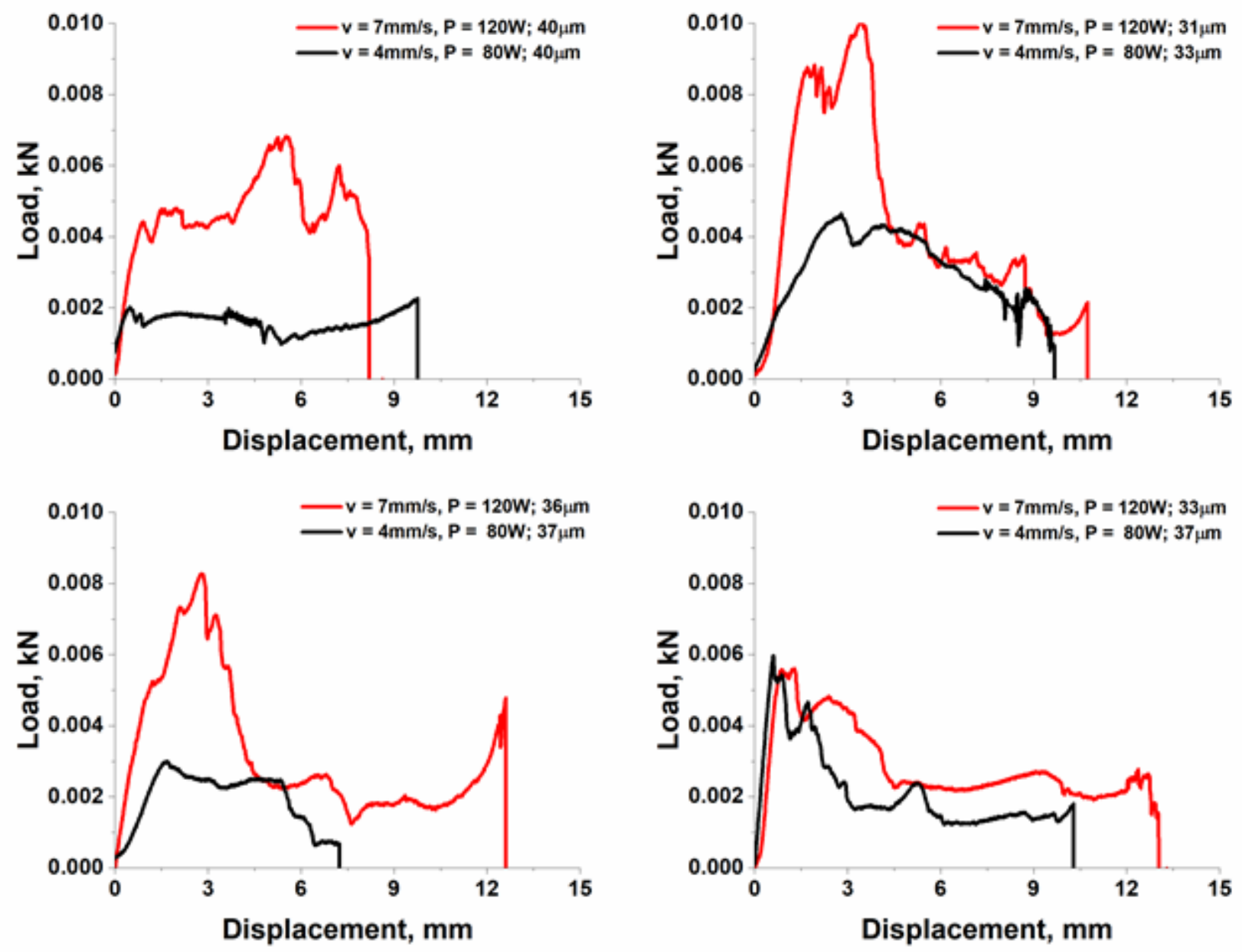

\section{Figure 16}

Load - displacement plots for peel-off tests on welding between $50 \mu \mathrm{m}$ Al films - white PP films. 

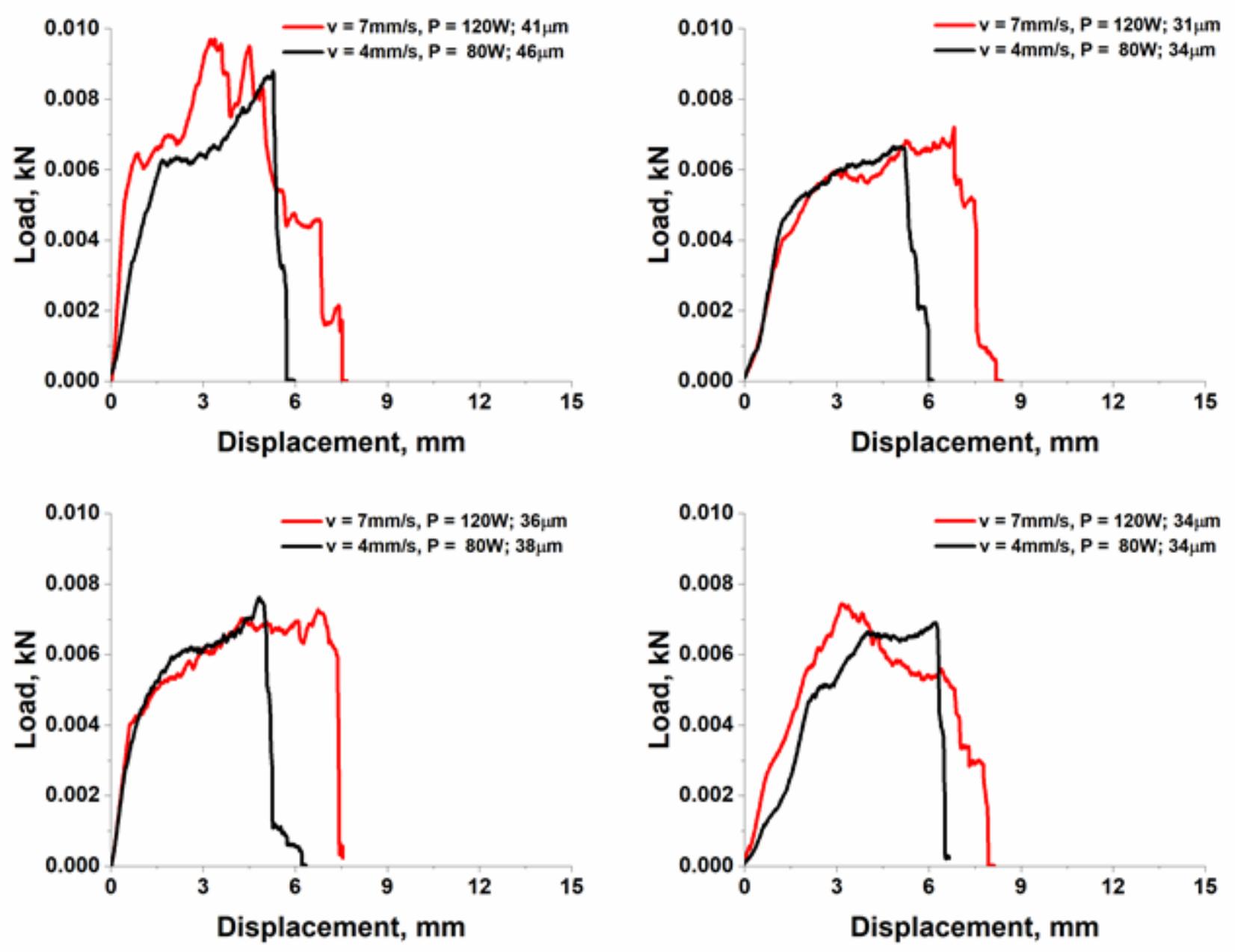

Figure 17

Load - displacement plots for peel-off tests on welding between $50 \mu \mathrm{m}$ Al films - transparent PP films.
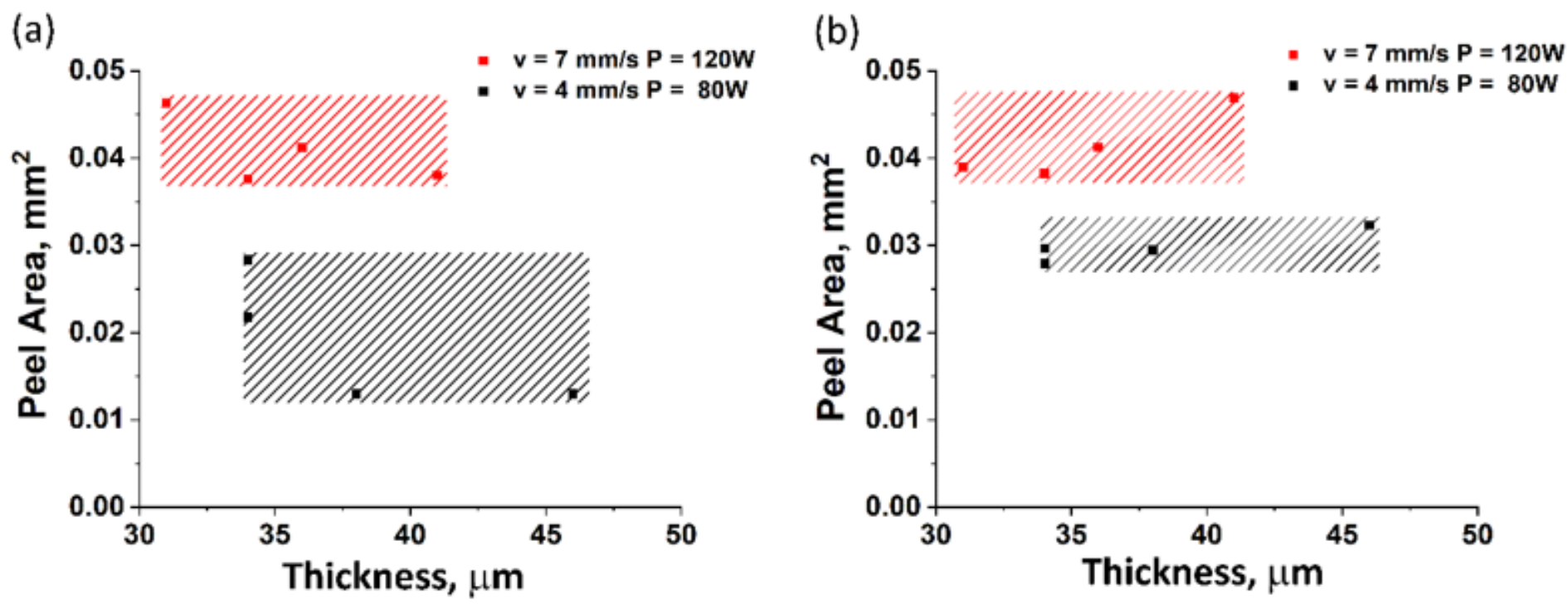

Figure 18

Energy required to tear the joint in a peel - off test (a) white PP; (b) transparent PP 